\title{
Current Research and Challenges in Bitumen Emulsion Manu- facturing and Its Properties
}

\author{
Ahmed Al-Mohammedawi ${ }^{1, *}$, Konrad Mollenhauer $^{1}$ \\ 1 Engineering and Maintenance of Road Infrastructure, Transportation Institute, University of Kassel, Mön- \\ chebergstraße 7, 34125 Kassel, Germany. \\ * Correspondence: a.al-mohammedawi@uni-kassel.de
}

\begin{abstract}
The global increase of road infrastructure and its impact on the environment requires serious attention to develop sustainable and environmentally friendly road materials. One group of those materials is produced by using bitumen emulsion. However, there are still scientific and technical obstacles standing against its regular application. The bitumen emulsion formulation process and compositional optimization are subjected to a high number of degrees of freedom. Consequently, obtaining the desired product is mostly based on a series of random and tedious trials because of the enormous number of tests to be carried out. The current review of the physicochemical formulation may indeed be extensively used in helping to reduce the number of unnecessary experimentations as well as discuss the vital aspects in the bitumen emulsion production process. Among these, emulsion stability, viscosity, droplet size (and distribution), bitumen emulsion chemistry, the function of the emulsion components, surfactant type, acids or alkalis, and additives are all discussed and used to define the emulsion's physical properties and reactivity. Besides, current developments in the mechanisms of breaking and setting processes are also summarized. It is discussed how emulsions are graded based on their reactivity, particle charge, and physical features. Two emulsification techniques are outlined namely the colloid mill method and the High Internal Phase Ratio (HIPR) method. Furthermore, some emulsion formulation tools/theories were identified and are explained. In that way, optimized formulations can be used to offer a practical guide for bitumen emulsion manufacturers when trying to formulate a well-defined bitumen emulsion for its use in pavement infrastructure rather than simply to meet standard specifications. This review paper aims to enable the ultimate potential of the bitumen emulsion in the field of cold recycling technology by further following up the research progress of bitumen emulsion manufacturing, therefore, this paper reviews and discusses the literature available up to now on this topic, in road engineering and emulsion chemistry.
\end{abstract}

Keywords: Bitumen Emulsion; Formulation; Emulsification Temperature.

\section{Introduction}

Bitumen emulsion is becoming more popular in the pavement construction sector. its applications are quite diverse, including cold recycling mixtures, tack coating, and surface treatment. Bitumen emulsions are an innovative method for liquefying bitumen by dispersing it in water. Bitumen emulsions have a significant advantage over hot bitumen since their operations need less energy because their viscosity is lower than that of hot bitumen. Furthermore, there are fewer hazards of fire and burns, and the process consumes less energy [1]. As a result, the cold mix emits less ozone-depleting hydrocarbons [2]. As an emulsion, bitumen emulsion is considered as an oil in water $(\mathrm{O} / \mathrm{W})$ emulsion system with water (or soap) as the continuous phase and bitumen as the dispersed phase. For phase compatibility, non-ionic, anionic, or cationic surfactants are added at a concentration of 1-2 weight percent of the total bitumen emulsion mass. According to industrial experience [3], the proper emulsion for road applications has a high bitumen content which normally ranges from 60 to $70 \%$ with a unimodal droplet size distribution and with 
an average droplet size ranging from 5 to $15 \mu \mathrm{m}$. Surfactants lower the viscosity of the system in comparison to the initial viscosity of the bitumen. The amphiphile molecule (surfactant) prevents droplet coalescence by decreasing the interfacial tension between bitumen and water, thereby stabilizing the system, and allowing emulsification [4]. Bitumen emulsion's main properties including type, average drop size, size distribution, rheology, and stability as well as its further use properties such as adhesion on the substrate must be tailored according to the pavement application (i.e., cold recycling, chip sealing). In most scenarios, the challenge during formulation is to get the desired result by selecting the appropriate components (surfactant, bitumen, aqueous phase) and their quantities. Then, through a potentially complicated procedure, combine them to form an emulsion. The optimization of the formulation and emulsification technique may be made reasonably straightforward by segregating and treating the different factors independently [3], [5]. Bituminous emulsions have been subjected to comparably little scientific study and even fewer publications in the area of formulations techniques and chemistry.

This review paper, therefore, aims at consolidating and examining the literature available on this subject, which is relatively extensively scattered across the literature and patents in various research fields, in order to further ultimate the application of cold bitumen technology in practice.

\section{Bitumen Emulsion Composition and Classification}

\subsection{Overview}

Bitumen emulsions are composed of water, surfactant, and bitumen itself. The emulsion is formed in two phases, using two immiscible liquids. Thanks to the electrostatic charges induced by the surfactant, the emulsion particles are suspended in the aqueous phase. Within this concept, surfactants can be defined as emulsifying agents that are active on the surface of the emulsified substances; thus, they are known as surfactants (surface active agents). Usually, $50 \%-75 \%$ of the emulsion is bitumen therefore, it is considered the most important component of bitumen emulsion [4].

\subsection{Bitumen}

Bitumen is known as a complex material that resulted from crude oil distillation. Bitumen is used in various construction sectors and mostly as a binder in asphalt pavement [6], [7] [4], [8], [9]. Bitumen can be described as a mixture of four broad chemical groups resins, asphaltenes, aromatics and saturates. The first two groups, due to their basic and acid functional groups, are considered the most polar compounds, therefore, they affect the interfacial properties affected [10]. The mechanism behind that is, these polar compounds can migrate and adhere to the water when bitumen droplets are emulsified in water. In that way, they can act as natural surfactants [11]., other components, such as wax crystals and naphthenic acids, can also act as a natural surfactant and affect the interfacial property of the bitumen water system but only in the case of low or high pH aqueous phase [12], [13] [14] [15], [16]. Thus, bitumen type and source are paramount parameters in the chemical interaction of the surfactants with the bitumen in producing the emulsions.

\subsection{Surfactant}

Surfactant's basic function is to reduce the surface tension of an emulsion and prevent the coalescence of the droplets. Besides, they control bitumen emulsion characteristics for instance stability, viscosity, breaking, and adhesivity. The latter is very important in the strength development of cold recycled mixture [4], [17]. The majority of surfactants have been utilized in the emulsification of bitumen. Anionic surfactants were the most common in the beginning, but cationic surfactants have gradually taken control since the 1950s [18].

A surfactant molecule consists of two parts namely the polar (hydrophilic head group) and a non-polar (hydrophobic chain group). The first makes it water-soluble, and this group is particularly crucial for the aqueous surfactant solution characteristics [19]. Bitumen emulsions are categorized as anionic, cationic, non-ionic, or zwitterionic based 
on the charge carried by the head group [20]. In general, cationic surfactants are fatty amines such as imidazolines, amidoamines, and diamines [21] that can be converted into soap by mixing them with suitable acid normally $\mathrm{HCl}$, as shown in Figure 1 . it can be seen that the outcomes from this reaction are ammonium compounds that have nitrogen (N) atoms with a positive charge on their head group ( $\mathrm{R}-\mathrm{NH} 3+\mathrm{Cl}-$ ). Electrovalent and polar head groups have a positive charge, and this charge is migrated to the bitumen droplet surface.
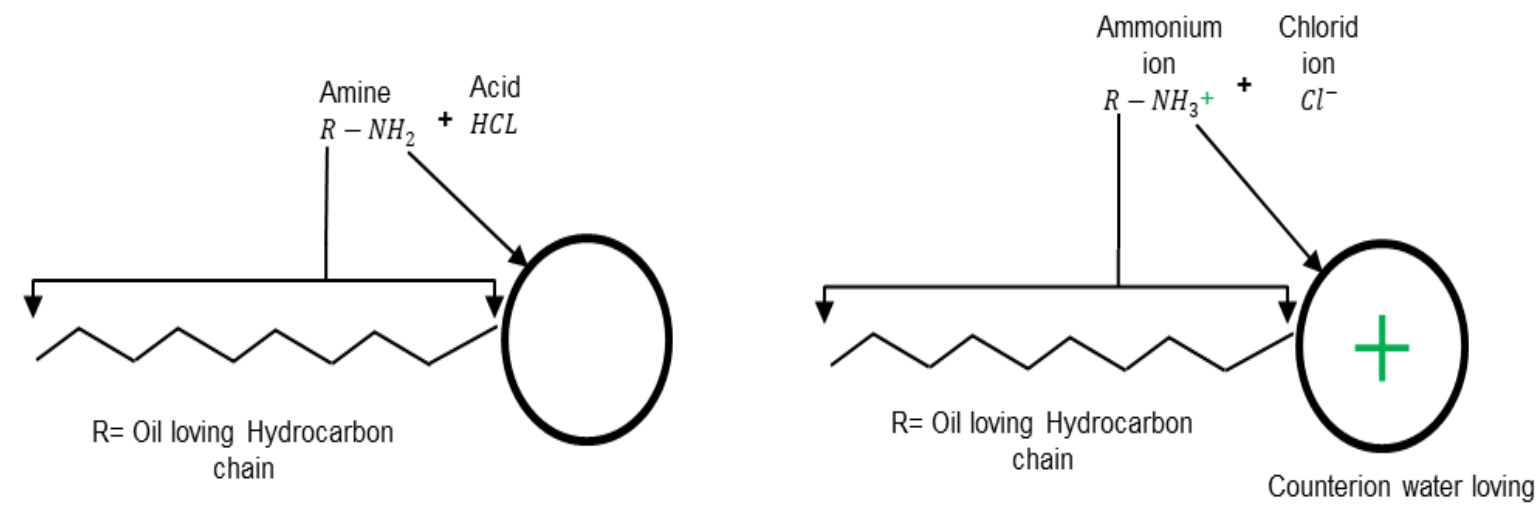

Figure 1. Example of a cationic soap production

Anionic surfactants are fatty acids such as lignin, tall oil, and rosin extracted from trees [22], [23]. Again, it is converted to soap by reaction with an alkali, usually, sodium hydroxide $(\mathrm{NaOH})$, as shown in Figure 2. The result is the carboxylate compounds with negatively charged oxygen $(\mathrm{O})$ atoms in their head group (R-COO-Na +). Electrovalent and polar head groups are negatively charged, and their positive charge is migrated to the surface of the bitumen droplet. In addition, fatty quaternary ammonium salts are another type of emulsifier used to make cationic emulsions. These types of surfactants are suitable and stable cationic surfactants because they are water-soluble salts and require no acid addition [21], [24], [25].
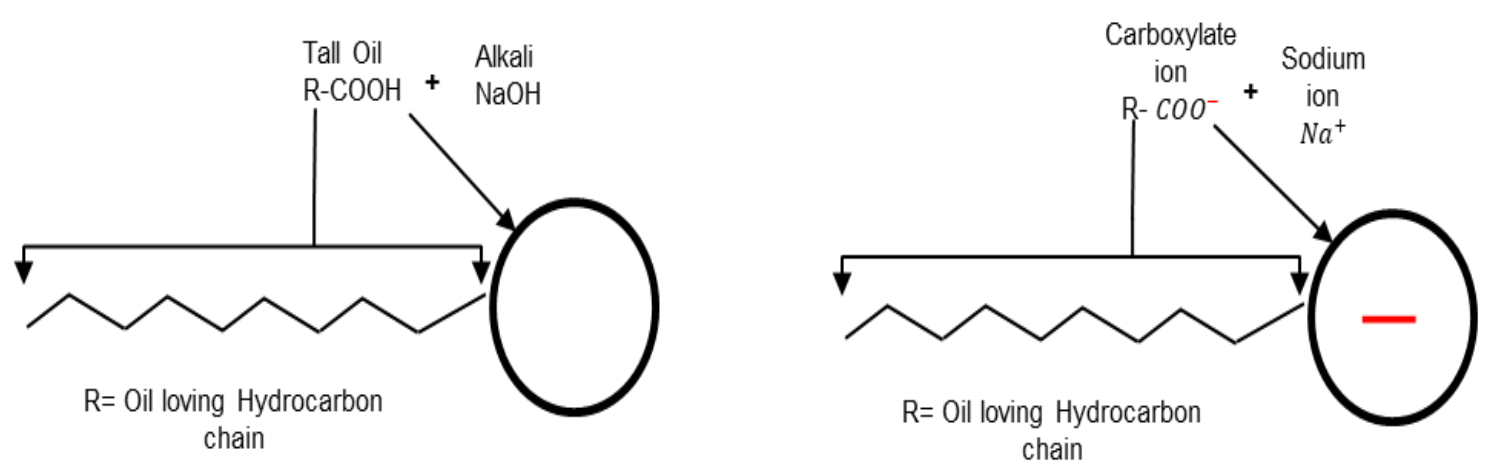

Counterion water loving

Figure 2. Example of an anionic soap production

\subsection{Bitumen Emulsion Classification}

Emulsions can also be categorized by the rate at which droplets of bitumen coalescence and return to bitumen. This is related to the rate at which the emulsion becomes unstable and breaks after mixing with aggregate and/or filler. Bitumen emulsions are divided into Rapid-Setting (RS), M-Setting (MS), and Slow-Setting (SS). In addition, bitumen 
emulsions are classified based on EN 13808 [26] with various letters and numbers indicating viscosity and basic bitumen type. Table 1 shows the abbreviations for cationic emulsions [27]. For example, C69BF3 70/100 is a cationic bitumen emulsion made from 70/100 pen-grade bitumen with a $69 \%$ bitumen fraction that contains more than $3 \%(\mathrm{~m} / \mathrm{m})$ flux and breaking class 3 .

Table 1. Cationic emulsion abbreviated designation [27]

\begin{tabular}{|c|c|c|}
\hline Character & Designation & Standard \\
\hline $\mathrm{C}$ & Cationic bitumen emulsion & EN 1430 \\
\hline two-digit & Nominal binder content as a & EN 1428 \\
\hline \multirow{3}{*}{ number } & $\%$ by mass & EN 1431 \\
\hline & Type of binder & \\
\hline & & EN 12591 \\
\hline B & Bitumen grade & \\
\hline $\mathrm{P}$ & Addition of polymers & EN 14023 \\
\hline $\mathrm{F}$ & $\begin{array}{c}\text { Addition of more than } 3 \% \text { by mass } \\
\text { of flux }\end{array}$ & \\
\hline 2 to 10 & Breaking value class & EN 13808 \\
\hline
\end{tabular}

\section{Bitumen Emulsion Properties}

The most essential performance requirements of bitumen emulsions are stability, viscosity, breaking, adhesion, droplet size, and dispersion. The perfect emulsion is stable under the conditions of storage, transport, and application, but it should return to bitumen quickly after application, leaving a binder with the properties of the original bitumen, firmly adhering to the aggregate, and consequently providing enough bearing capacity for timely construction process [4].

\subsection{Bitumen emulsion stability}

Emulsion stability is an important parameter to consider and monitor when producing a bitumen emulsion. The tendency of an emulsion to alter characteristics over time is referred to as its emulsion stability. [28]. In general, it is controlled by the interactions between the surfactant and water/bitumen interfaces. During the storage, bitumen droplets begin to approach one another due to low surfactants concentration at the interfaces therefore contact between two droplets is expected and what is called the flocculation phenomenon is occurred [29]. When there is no mechanical agitation in the system, this is what happens during emulsion storage. If steps are not taken to reverse flocculation, coalescence can occur (see Figure 3). With coalescence, the surfactant layer between the droplets is compromised allowing the droplets to contact one another. During this process, water can become trapped within the new larger droplet. Since there no longer remains a physical barrier between the emulsion droplets, the droplets cannot be separated [30]. This last mechanism has substantial dependence on formulation [31], in terms of the bitumen grade, bitumen temperature, soap temperature, and surfactant type [32]-[34]. During storage, bitumen emulsion is subjected to gravitational force leading to dragging the bitumen droplets down to the bottom due to the difference in densities of the disperse and the continuous phases forming the sedimentation phenomenon. 
Stable Emulsion

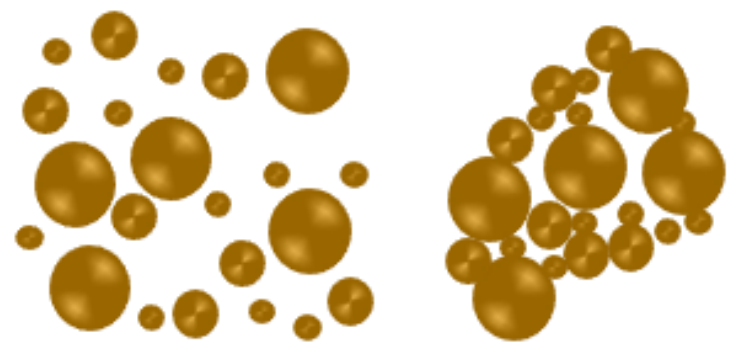

Coalescence

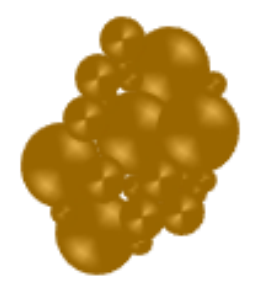

Sedimentation

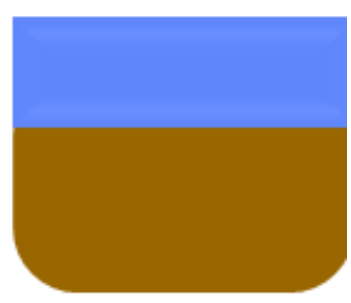

Figure 3. Bitumen emulsion flocculation, coalescence, and sedimentation

\subsection{Bitumen emulsions viscosity}

Emulsion viscosity is an important performance characteristic of bitumen emulsions. In cold recycled mixes, low viscous emulsions may drain off the aggregate or affect the aggregate/binder adhesion evolution, which in turn affects the gaining of the mechanical strength. On the other hand, in chip seal, low viscosity emulsions are likely to run off the road, whereas too viscous emulsions may not distribute well over the surface. In this manner, bitumen emulsion viscosity affects the performance of the final product. Bitumen emulsion viscosity is affected by factors such as emulsion particle size and particle size distribution [35], the bitumen to water ratio [36], the surfactant type [37], and the presence of salt in the bitumen [38] which can lead to higher viscosity during storage of the emulsion [34].

However, it is a challenging task to regulate these variables autonomously during emulsion manufacturing. This is because certain characteristics for instance surfactant concentration and interfacial tension are all dependent parameters. For example, any change in the interfacial tension will change the droplet's size (and its distribution) which in turn, changes the bitumen emulsion viscosity. Usually, the emulsion viscosity raises as the average droplet size decreases, while the emulsion viscosity drops down as the droplet size distribution gets narrower. [39]-[41]. Besides, the emulsion viscosity also can be affected by the surfactant content as it can be increased when the surfactant content is increased due to the droplet's size reduction. In contrast, when the viscosity goes down the system will experience an ultra-low interfacial tension [42]. This system is completely near to the ideal formulation which will be discussed in detail in section 7.5, and droplet size is often quite tiny. Nevertheless, these systems are exceedingly unstable, for example, droplet coalescence happens very quickly, even after emulsification directly. Besides, the emulsion viscosity can be also affected by the surfactant chemical structure. furthermore, some surfactants have a unique effect as they can form multiple emulsions (W/O/W). Therefore, the emulsion viscosity is very important to be controlled as it affects the product during the manufacturing, storage, and mechanical performance during the service [38], [40], [43].

\subsection{Bitumen emulsion breaking}

Bitumen emulsion is intended to break when they come into contact with aggregates, leaving a binder layer on and between the aggregate particles. The overall process, also known as emulsion settling, is a complicated phenomenon that determines the ultimate performance of the pavement. Emulsion breaking is not comprehensively understood, and there are numerous approaches of explanation for related phenomena. Various processes occur at the same time during the breaking. On this basis, several research on bitumen emulsion breaking mechanisms have been conducted, focusing primarily on the surfactant, the kind and amount of additive, and the bitumen emulsion preparation conditions. Marchal et al. noticed that the quantity of surfactant that is not attached on bitumen droplets or adsorbed on the surface of the aggregate has a significant impact on the bitumen emulsion's breaking speed [49], [50]. According to Gorman et al., the most critical parameters influencing the breaking process of bitumen emulsion are bitumen emulsion 
characteristics and aggregate surface properties [44]. According to Hagen et al., the surface properties of the aggregate have a significant impact on the breaking speed and adhesion of bitumen emulsion [45]. Lyklema [46] and Castillo [47] believe that surfactant desorption on the bitumen surface and adsorption on the aggregate surface influence bitumen emulsion breaking. Read and Whiteoak revealed that the higher temperature is, the higher the breaking speed [4]. In general, breaking is regulated by physiochemical interactions [48]. Therefore, it essentially involves the different breaking mechanisms such as surfactant adsorption breaking mechanism, water evaporation breaking mechanism, $\mathrm{pH}$ change breaking mechanism [5].

\subsubsection{Surfactant adsorption breaking mechanism}

Molecules of the surfactant are disseminated among bitumen globules, suspended in water, with micelles being formed by some of their ions, but in stable conditions, the emulsion is in equilibrium (Figure 4), until adsorption of these ions by polarized mineral aggregates. Consequently, the emulsion breaks at a rate depending on surfactant adsorption in mineral aggregate, affected by the chemical properties of the latter and the surface area [49], [50]. A schema of the breaking mechanism due to adsorption is shown in Figure 4. Poirier et al. [51] examined the adsorption of a cationic surfactant at the bitumen/water interface in order to estimate the stability of bitumen emulsions. The adsorbed quantity of the surfactant is tracked in this investigation by varying concentrations in the bulk aqueous phase. The results revealed that at the surfactant's CMC, the adsorption isotherm exhibits a plateau, but no multilayer adsorption occurs. Furthermore, it was found that there is a strong correlation between the adsorbed amount and the electrokinetic potential variations [51].

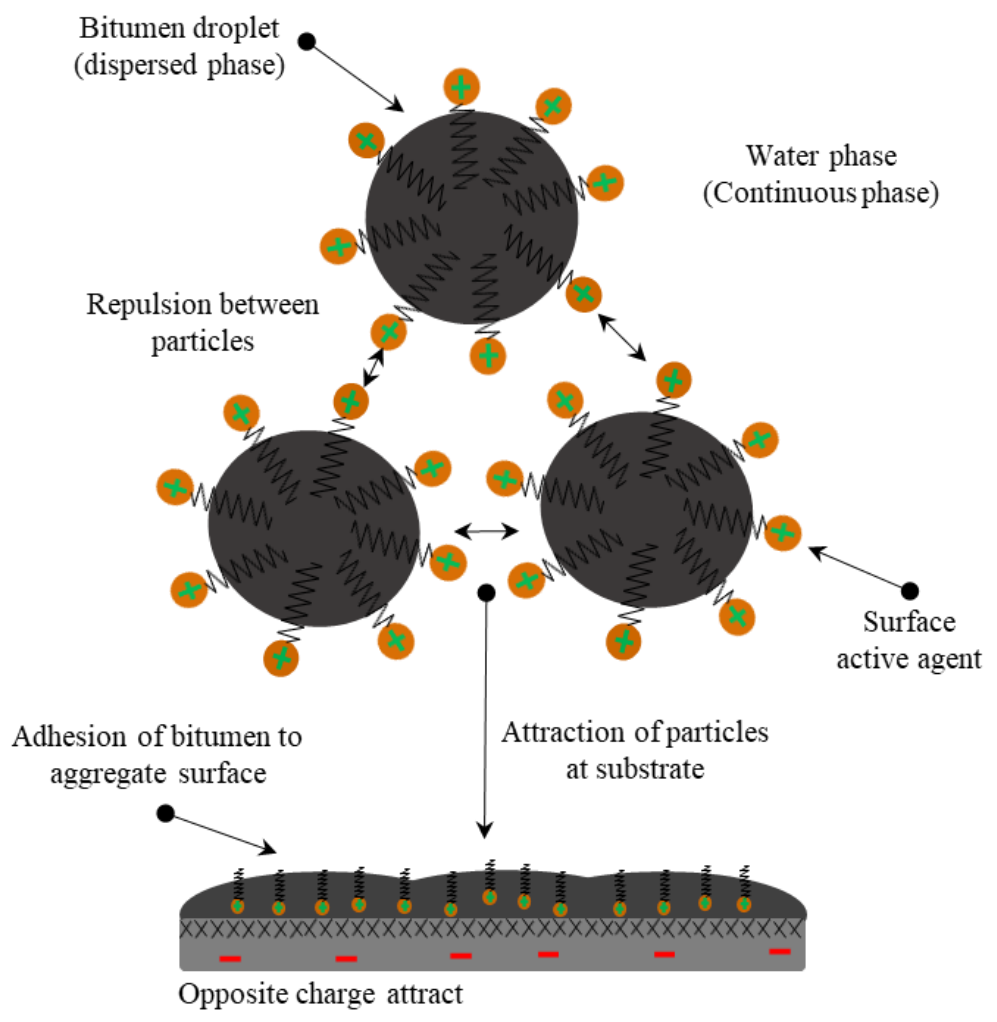

Figure 4. Schema of bitumen emulsion droplet changes adapted from [4]

\subsubsection{Water evaporation breaking mechanism}

Water evaporation from the emulsion, affected by environmental conditions including wind speed, humidity, and temperature, has major impacts on breaking. Evaporation 
causes the concentration of bitumen droplets in the emulsion to increase, thus increasing the inter-droplet contact and relative homogenization, diffusing surfactants into the solution from the interfaces to form surfactant micelles, due to decreasing the interfacial area. In industrial applications (e.g., cement and asphalt pavement construction), water is characteristically trapped within structures; similarly, in bitumen, a significant quantity of water is sealed in closed pores, and evaporative processes can go on for years, which is why CRM takes many years to reach full strength. The evaporative breaking process is represented in Figure 4 [52].

\subsection{3. $\mathrm{pH}$ change breaking mechanism}

Acidic or alkaline reactions cause surfactants to react, forming surfactant soaps, due to surfactants' surface charge being dependent on $\mathrm{pH}$, as discussed previously. For instance, cationic surfactants such as fatty amines are soluble in acid but insoluble in water. Fatty amines are dissolved by $\mathrm{HCl}$ to produce water-soluble soaps, which can then be blended in the colloid mill with hot bitumen to yield bitumen emulsion. surfactants' function can therefore be compromised when cement or mineral aggregate engages with cationic emulsions, due to increased $\mathrm{pH}$; cement is particularly potent in affecting the $\mathrm{pH}$ of cationic emulsion. Consequently, the setting time and stability of bitumen emulsions are normally gauged concerning active filler [53]. It should be noted in this regard that some surfactants, including quaternary amines, retain their functionality even when $\mathrm{pH}$ changes [5].

\subsection{Bitumen emulsion adhesivity}

Considering the right type of aggregate and bitumen emulsion is very important to characterize the compatibility of CRM in terms of adhesion performance and water sensitivity. Therefore, the choice of the surfactant in accordance with the type of mineral material can be optimized to achieve the maximum efficiency of preparation and use of the bitumen emulsion. However, the research on the surface characteristics of the aggregate and bitumen emulsion chemistry is rarely reported. Meanwhile, each aggregate-bitumen emulsion combination has a distinct chemical composition, which influences the connection between the aggregate and bitumen [44], [54], [55] and therefore affects CRM mechanical performance (i.e. bearing capacity and water damage sensitivity) [56]-[58]. In the case of cationic emulsions, the use of an aggregate with a surface charge similar to that of bitumen, such as limestone, results in poor adhesion between bitumen and aggregate, as well as a delay in the curing time [59], [60]. This phenomenon, as shown in Figure 5, is governed by the physiochemical adsorption of bitumen and surfactant onto mineral filler/and or aggregate surface, which is in turn controlled by several factors including Van der Waals attraction forces, electrostatic forces, or covalent and electrovalent bindings, and the film adhesion. The formation of adhesion film depends on the bitumen and aggregate type. In an anionic emulsion, bitumen droplets are surrounded by a negative charge. If the anionic bitumen emulsion is mixed with an acid-nature aggregate (i.e., silica), emulsion could be destabilized rapidly, and therefore early adhesion. Recently, a study on molecular dynamic simulation and conductivity experiments was conducted to systematically explore the adsorption of different anionic surfactants on the calcium carbonate and silica. Results indicated that the adsorption of the anionic surfactants on the $\mathrm{SiO} 2$ surface was stronger than that on the $\mathrm{CaCO} 3$ surface [61]. 


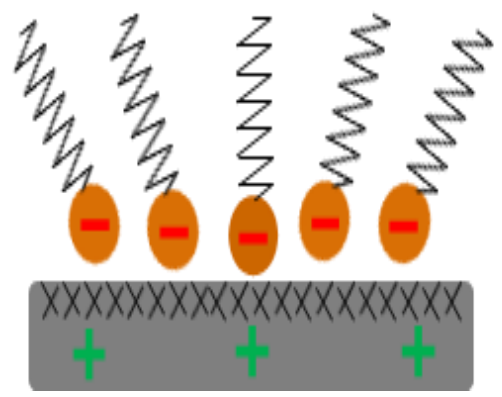

(A)

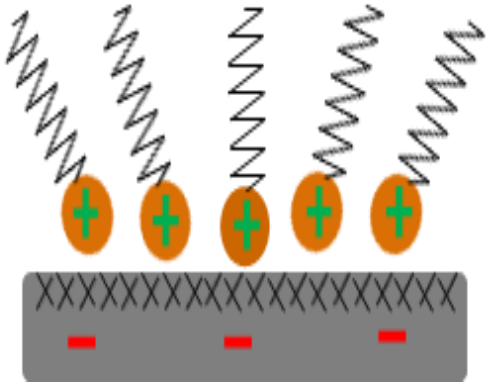

(B)

Figure 5. Surfactant adsorption by ionic change: (A) Anionic; (B) Cationic

When cationic bitumen emulsion is combined with a basic aggregate, however, a possible interaction between the surfactant and the carbonate anion might occur. Adsorption of the produced salt by the solid surface improves adhesion. Hu 2009 et al, carried out a study on cement bitumen emulsion mortar to investigate the adsorption of different bitumen emulsions on cement grain surface by the means of characterizing the particle size variation using a laser particle size analyzer. It was found that bitumen droplets in cationic bitumen emulsion were much more likely to be adsorbed to cement grains in comparison with those in anionic bitumen emulsion [62]. These chemical reactions can explain why cationic bitumen emulsions are preferred in cold mixes. In addition, the bitumen adsorption on the substrate can be also optimized by lowering the surfactant concentration slightly below the critical micelle concentration (CMC). Meanwhile, surfactant concentration higher than $\mathrm{CMC}$ is necessary to increase the stability of the unstable thermodynamic emulsion [63]. The critical micelle concentration (CMC) is an important characteristic that can sometimes be forgotten or left out of the discussion when during the emulsification process; it is the surfactant concentration where adding any more surfactants would cause micelles to form as illustrated in Figure 12. It depends on the surfactant, medium (usually water), temperature, pressure, and salinity.

Al-Mohammedawi and Mollenhauer 2020 conducted a study on the effect of the chemical nature of fillers (Both acidic and basic fillers) on the mechanical properties of cationic bitumen emulsion mastic. It was found that the filler with basic nature shows high reactivity in terms of $\mathrm{pH}$ value which is reflected in the fatigue and rheological performance which was believed due to the high filler/ bitumen emulsion compatibility [53], [64]. However, this study needs to be supported by microscopic and microstructure analysis in order to get more information about the surfactant and bitumen adsorption on filler particles. In this regard, there is a growing research interest in employing the enhanced mesoscopic methods that can be used efficiently to identify the colloidal forces between the bitumen droplets in the aqueous phase [65]-[67] and also between bitumen and aggregate [68]-[73]. Knowing that these techniques are normally applied for Athabasca bitumen it can be adapted to be used in bitumen emulsion research area as both fields share the same underlying physical chemistry [10], [14], [74]- [78]. In that way, several investigations have been conducted to investigate the surfactant/bitumen compatibility using different techniques such as surface free energy, fluorescence spectroscopy, neutron scattering, interfacial viscoelasticity, and Raman spectroscopy [79]-[85]. Jin et al. (2013) investigated the synthesis of a composite surfactant using an OP-10 cationic surfactant [86]. The impacts of the manufacture parameters and formulation on the surfactant emulsification properties, service performance, and surface activity were investigated. Tan et al. (2013) discovered that surfactants have a considerable retarding impact on cement hydration, which is related to the kinds of surfactants and their doses [87]. As a result, a suitable surfactant with a low retarding impact on active filler and its appropriate dose is advised. 
Consequently, when bitumen emulsions are employed in cold asphalt mixtures, the chemical characteristics of surfactants and aggregates should be considered throughout the design process to achieve the desired adhesive property [88]-[90].

\subsection{Droplet size and droplet size distribution}

The granulometry of an emulsion can be characterized as a function of mass, volume, and surface of droplets. Nonetheless, the mean average size is the most commonly used definition. Emulsions are classified into two types based on droplet size: macro-emulsions and micro-emulsions. Droplet sizes in macro-emulsions are in the size range of micrometers $(\mu \mathrm{m})$, whereas droplet sizes in micro-emulsions are in the size range of nanometers $(\mathrm{nm})$. Microemulsions are thermodynamically stable which means having high stability due to their small droplet size, but macroemulsions are thermodynamically unstable (the larger droplet size the lower stability) [91]-[93]. The size of the droplet is determined by several variables, as shown in Figure 6. These variables are also significant in emulsion stability [94]. During the emulsion manufacturing process, bitumen emulsion with various droplet sizes is produced. This is due to mechanical factors such as interface shearing, gap width, and so on, which results in polydispersity [95], [96]. Increasing the emulsification time typically results in smaller droplets and narrower distribution [97]. The speed of emulsification has a comparable influence on droplet size and its distribution. Bitumen emulsion particles are typically $0.1-20 \mu \mathrm{m}$ in size [5], [98], Not only does droplet size affect stability, but it can also change the emulsion's rheological characteristics [19], [91], [99]. Moreover, the content of the surfactant has a significant impact on the size of the droplets. Smaller droplets are formed when the surfactant dosage rises. This may be explained by an increase in the ability to cover a larger interfacial surface as well as a quicker surfactant migration kinetic to the bitumen-water interface. According to Baumgardner, the particle size of bitumen emulsion may be varied by the formulation, raw ingredients (i.e., surfactant), and manufacturing equipment [98]. In this regard, Liu et al. pointed out that surfactants with increased surface activity resulted in emulsions with reduced average particle size diameters. They came to the conclusion that increasing the surfactant dose lowered the average particle size diameter [100]. These observations are later verified by [101]. Similarly, Gingras et al. indicated that when mill rotor speed augmented and emulsification temperatures dropped down [3], the average particle size decreases. The findings of [102] corroborated this notion. Gingras et al. investigated bitumen content and its impact on particle size. As the bitumen content reduced, they observed a reduction in droplet size. They ascribed this interaction to particles colliding more frequently when the bitumen content is higher [3]. Gutierrez et al., on the other hand, have a different observation. They examined higher content of bitumen than what Gingras did, but their observations did not coincide [102]. More study might lead to a more complete explanation; however, it is apparent that the bitumen content influences the particle size of the resultant emulsion. The preceding sections offered an overview of the variables that determine bitumen emulsion characteristics. However, it is nearly impossible to change one emulsion characteristic without affecting others. Figure 6 illustrates this interrelationship. 


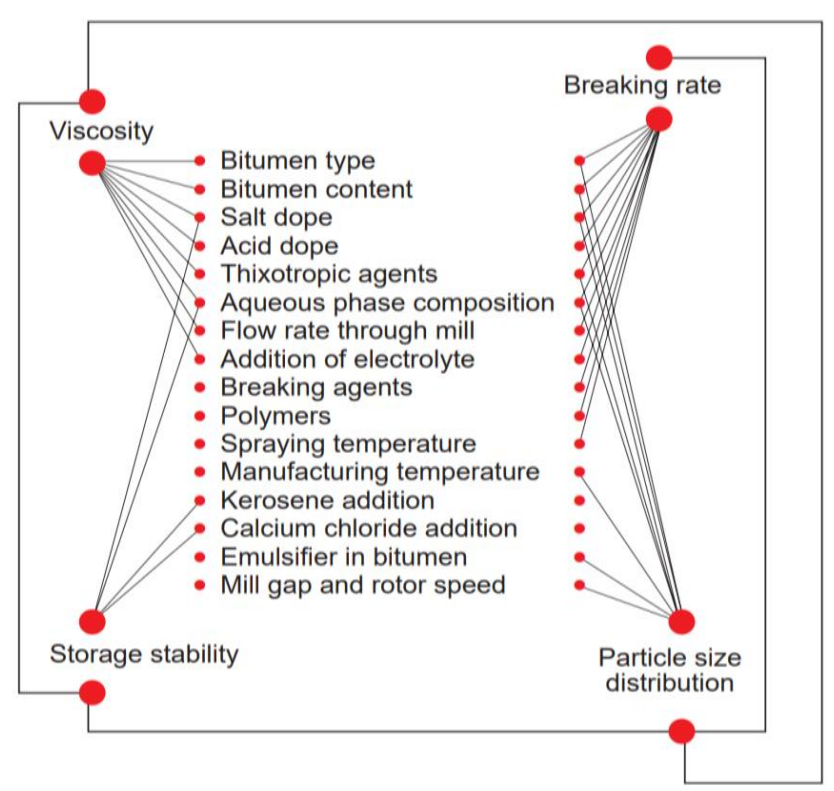

Figure 6. Interrelationship between manufacturing variables and properties for bitumen emulsions [103]

\section{Bitumen Emulsion Manufacture}

The production of bitumen emulsions is a complex process. In the industry, formulators must consider several aspects linked not only to the production process but also to the end attributes for which the emulsion has been developed. Mechanical parameters such as the emulsification method and its variables must be managed during the production of a bitumen emulsion. [3], [104], [105]. There are two methods to fabricate bitumen emulsions namely colloid mill and High Internal Phase Ratio (HIPR). Colloid mill is the most commonly used equipment for emulsion manufacturing. Colloid mill, as illustrated in Figure 7, consists of a fast rotor (1000-6000 revs/min) in a stator; thanks to the generated shear forces, the bitumen is torn and stretched into globules, which are coated by surfactant and thus electrically charged. The mill's geometric characteristics are instrumental in the distribution of particle sizes, with a common adjustable clearance range of 0.25 to 0.5 $\mathrm{mm}$ between the rotor and stator [106]. The colloid mill receives firstly surfactant mixed with water with temperatures ranging from $40-65{ }^{\circ} \mathrm{C}$. Afterward, hot bitumen at 120 $180^{\circ} \mathrm{C}$, with a viscosity of about $0.2 \mathrm{~Pa}$.s, which is suitable for emulsification, is then provided in the colloid mill gradually (see Figure 8 ). In some cases, emulsions may be thermally unstable, or short-lived (i.e., stiffer bitumen or polymer-modified). During the emulsification process, the water phase compensates for the temperature to be below $90^{\circ} \mathrm{C}$, improving thermal stability [107]. For stiffer bitumen, higher temperatures should be provided, and more mill power to generate bitumen droplets of the required size. However, the boiling point should be avoided [4], [108]. For cold recycling purposes, emulsification generally occurs within a bitumen content of 60 to $70 \%$. Above this range, the fabrication is inefficient due to the formation of very large drop particles, and emulsions have little storage stability. Furthermore, the droplet size achieved by this approach ranges from 5 to $10 \mu \mathrm{m}$; tiny droplet sizes are quite difficult to generate [109], [110]. 


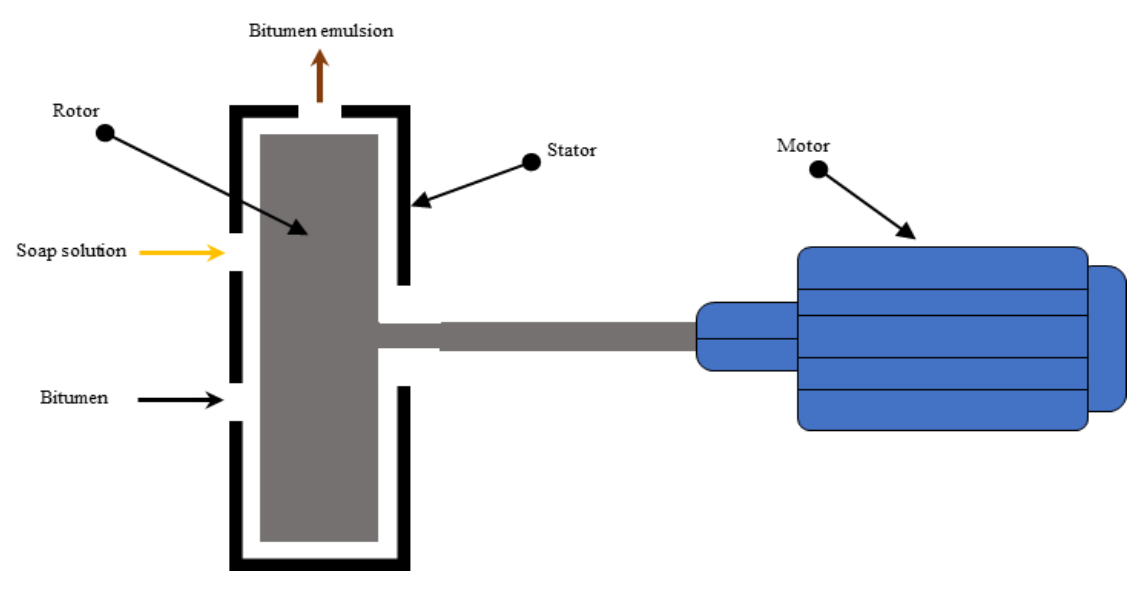

Figure 7. Colloid Mill Cross Section adapted from [110]

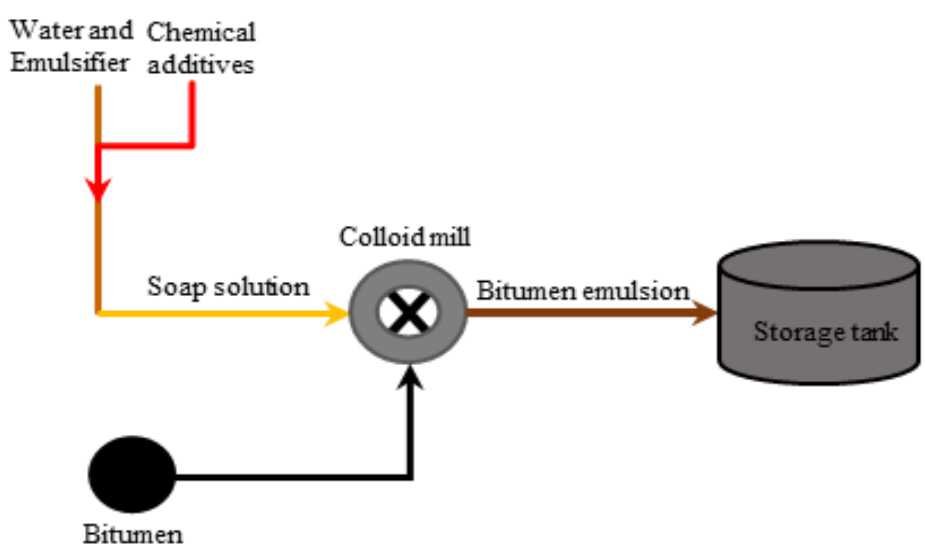

Figure 8. Schematic of a bitumen emulsion plant adapted from [4]

For smaller droplet sizes, another technique called High Internal Phase Ratio (HIPR) was introduced by Lissant et al. [111], [112]. Within this technique, Samanos performed research on the manufacturing of bitumen emulsions for use in asphalt pavement manufacturing and maintenance, intending to achieve controlled emulsion properties through the employment of a dispersion phase in a suitable mixer. Based on this study, a lot of the studies developed later [43], [108], [113] trying to optimize the manufacturing parameters (temperature of bitumen and soap, the shear rate, material composition, and bitumen basic properties) [43], [95], [114]. The HIPR approach (Figure 9) employs phase inversion, which considers the physicochemical characteristics and the concentration of each component during fabrication. As a result, the type of emulsion produced, as well as its characteristics, may be tailored. This process entails a direct blend of a very viscous phase (15000 Pas) with a second phase that is immiscible with the first and contains at least one surfactant. It produces a viscoelastic paste that may be diluted to the needed concentration of the dispersed phase using low shear (500-1500 rpm) and laminar flow. This process normally takes short time. This technique may produce monomodal emulsions with an extremely narrow particle size distribution and a small mean droplet size of around $1 \mu \mathrm{m}$. Furthermore, this technique is capable of producing concentrated and extremely concentrated bitumen emulsions (70-95\%) [102], [115]. The droplet size of the emulsions generated by this method may be easily modified by varying the rotating speed, formulation parameters, or the concentration of the dispersed phase utilized during manufacturing. Unimodal emulsions have a single particle size distribution (produced within this method), but bimodal emulsions have two controllable droplet sizes and distributions, as illustrated in Figure 10 [40], [116]-[118]. 


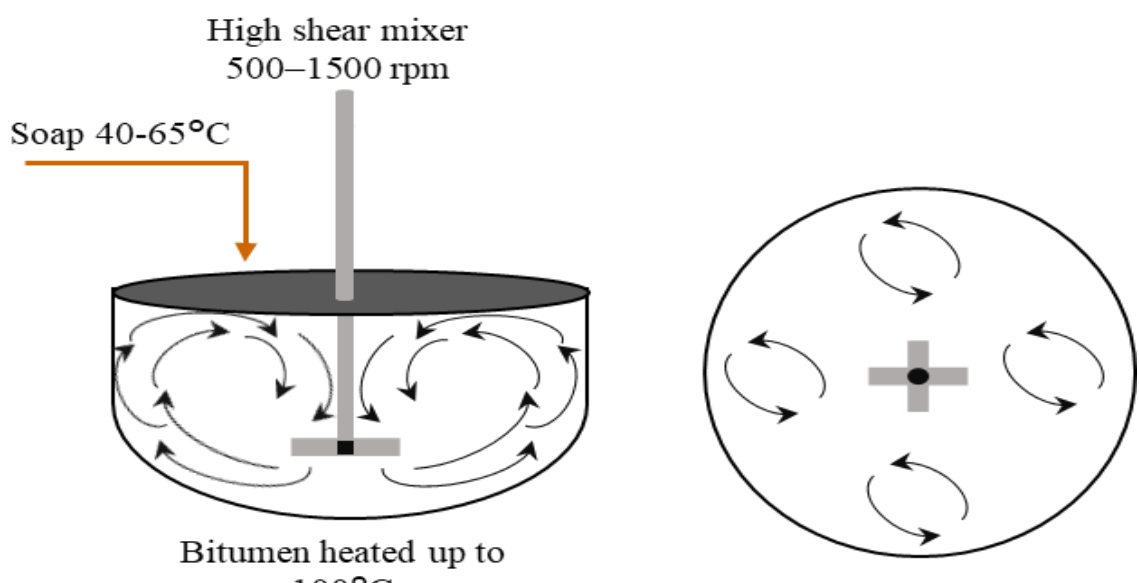

Figure 9. Schematic of a bitumen emulsion manufacturing using HIPR technique [113]

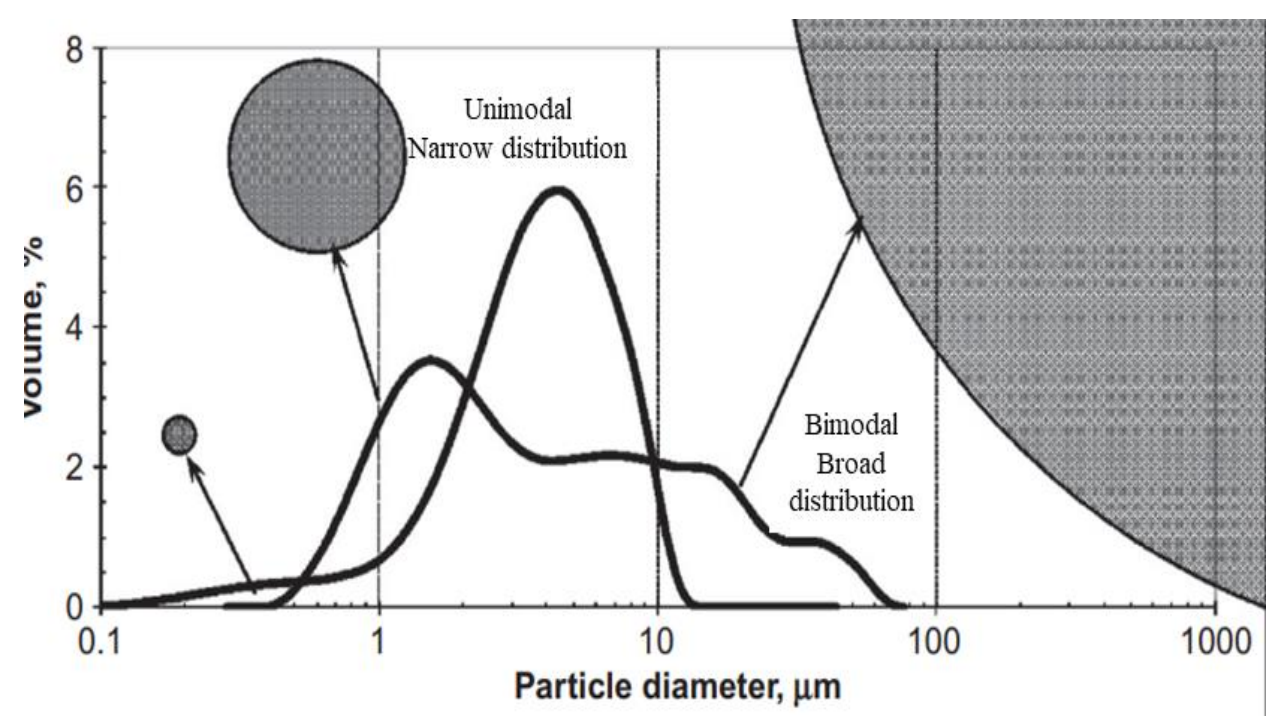

Figure 10. Unimodal and Bimodal Bitumen emulsion particle size distribution [117].

\section{Emulsification Temperature}

The emulsification temperature includes soap and bitumen temperatures as well as the resulted emulsion temperature. Playing around these temperatures could result in a bitumen emulsion with different properties. Therefore, these temperatures should be carefully defined and optimized along with the bitumen emulsion properties. This is significant because the boiling point can be reached during the emulsification process (this can be avoided by selecting the right soap/bitumen temperatures). The soap temperature has a significant impact on the solubility of ionic surfactants in water as the solubility upsurges with increasing temperature until it reaches a limit value known as the Krafft Point Temperature (KT). Below the Krafft temperature, surfactant micelles cannot be formed as shown in Figures 11 and 12 [119], [120] and the surfactant is insoluble [121], [122]. However, at the Krafft temperature, the surfactant's solubility increases dramatically, and additional temperature increment allows for micelle formation upon reaching the CMC [123]. This means that when temperatures rise, the hydrophilic character of ionic surfactants increases [124]. Non-ionic surfactants, particularly polyethoxylated molecules, have the opposite behavior. KT is also known as the critical micelle temperature as it is connected to the critical micelle concentration (CMC) of the surfactant as illustrated in Figure 12 [125], [126]. The mechanism, by which the bitumen droplets dispersion occurs, is the incorporation of the bitumen molecules into the micelle. Therefore, the temperature is then an important parameter in the formulation. 


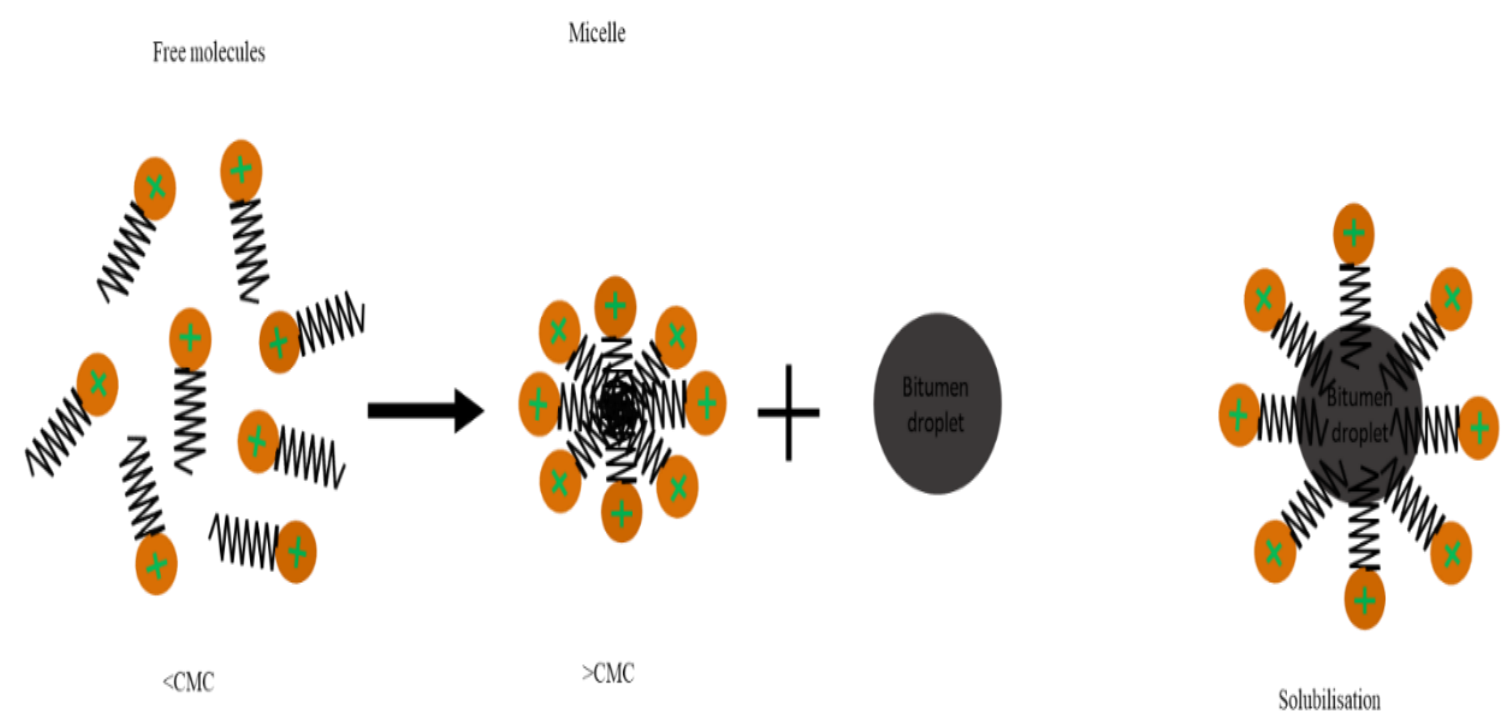

Figure 11. Schematics of micelle formation at concentrations above the CMC and bitumen droplet dispersion by micelle in the aqueous phase

When it comes to the bitumen, higher temperature favors the development of smaller bitumen droplets. In this regard, studies indicated that a maximum bitumen viscosity of $200 \mathrm{mPa}$.s is required for effective emulsification. This viscosity value cannot, in some cases, be achieved at manufacturing temperatures below $100{ }^{\circ} \mathrm{C}$, particularly when using modified bitumen [127]-[129] as the viscosity of modified bitumen is often greater than that of untreated bitumen. Nevertheless, Gingras et al. noticed that in some extreme instances, droplet size might be increased as a result of a temperature increase [108]. This can be explained by surfactant thermal fragility (thermal breaking at extremely high temperatures) or by the development of formulation as temperature rises (HLB declines, HLD approaches zero, and system approaches optimal formulation) [130]. This can cause an immediate coalescence of a droplet. Keeping in mind that, the surfactant ability to keep the droplets repel each other is not only required in the emulsification process only but also will be required at storage.

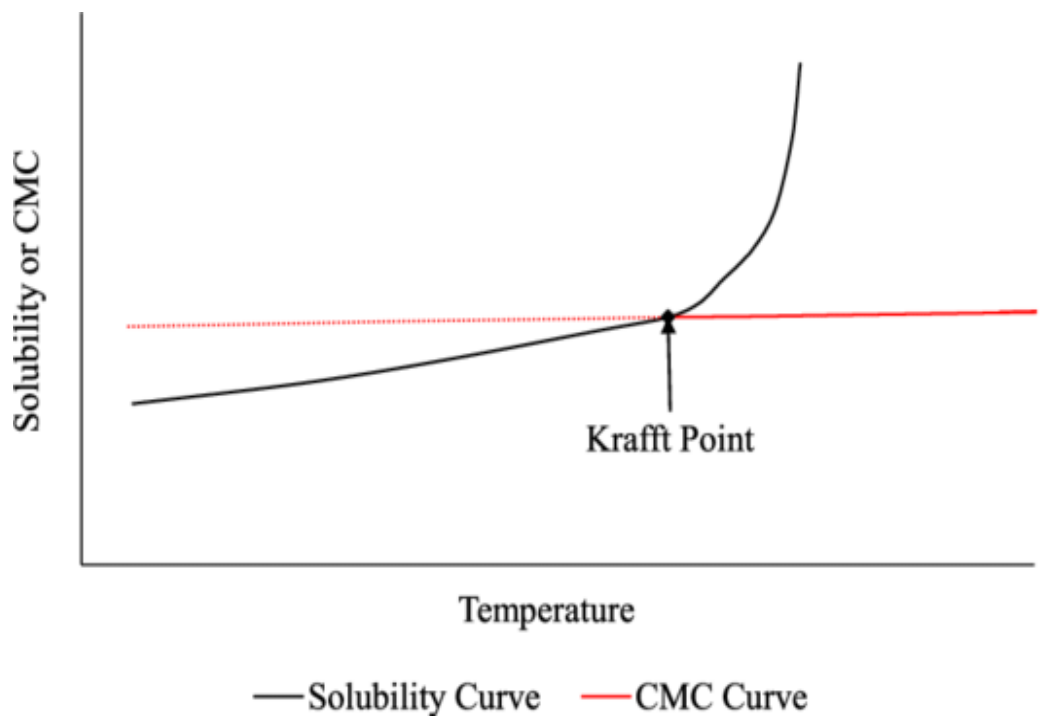

Figure 12. Conceptual chart of the Krafft point and CMC [131]

The temperature of the water phase and the temperature of the bitumen phase [132] can be used to determine the emulsification temperature using the equation below: 
$T w=T e+(T e-T b) *\left(\frac{C p b}{C p w}\right) *\left(\frac{b}{w}\right)$

$\mathrm{T}_{\mathrm{e}}=$ Temperature of emulsion ${ }^{\circ} \mathrm{C}$

$T_{b}=$ Temperature of bitumen ${ }^{\circ} \mathrm{C}$

$C_{p b}=$ Heat capacity of bitumen

$C_{p b}=1.90 \mathrm{~kJ} /{ }^{\circ} \mathrm{C} / \mathrm{kg}$

$C_{p w}=$ Heat capacity of water-phase

$C_{p w}=4.18 \mathrm{~kJ} /{ }^{\circ} \mathrm{C} / \mathrm{kg}$

$\mathrm{w}=\%$ water-phase

$\mathrm{b}=\%$ bitumen -phase

$T_{w}=$ Temperature of water-phase ${ }^{\circ} \mathrm{C}$

In addition, Baumgardner [98] proposed an empirical equation based on soap and bitumen percentages and temperatures. The emulsification temperature can be empirically calculated using the following equation [98].

$$
E T=\frac{(B w * B T * 0.5)+(S W * S T)}{(B w * 0.5)+S W}
$$

where:

$E_{T}=$ Emulsion temperature $\left({ }^{\circ} \mathrm{C}\right)$

$B_{w}=$ Bitumen weight $(\%)$

$B_{T}=$ Bitumen Temperature $\left({ }^{\circ} \mathrm{C}\right)$

$S_{W}=$ Soap solution weight $(\%)$

$S_{T}=$ Soap solution temperature $\left({ }^{\circ} \mathrm{C}\right)$

Both earlier equations don't take into account the emulsification time, or the energy induced by tearing or milling the bitumen which indeed causes a temperature rise as a function of emulsification time. Therefore, these parameters should be accounted for within the emulsification temperature estimation in order to obtain the required emulsion properties.

\section{Bitumen Emulsion Formulation-Related Parameters}

Formulators can change the final emulsion product by adjusting various formulation parameters. Among the other variables listed in Figure 6, they can change the surfactant, surfactant dosage, $\mathrm{pH}$, water characteristics, emulsification temperatures, milling speed, emulsification time, and stator rotor gap. The manufacturer, on the other hand, must understand how changing the formulation of the bitumen emulsion affects its material properties and performance. Several studies have been carried out to determine how changing the formulation parameters of a bitumen emulsion affects its performance and material properties. As previously stated, the type of surfactant used in an emulsion has a significant impact on the charge and breaking speed of an emulsion. Surfactants have a lipophilic tail and a hydrophilic head group. Different combinations of tails and heads result in different charges and properties for the final emulsion product. The amount of surfactant in a soap solution also influences the properties and performance of emulsions [5]. Pang et al. [133] studied the influence of surfactant dosage on emulsion residue rheological performance. They discovered that increasing the surfactant content increases emulsion viscosity and modulus at the same temperature and frequency. It was also discovered that a higher surfactant content increased resistance to bitumen emulsion mixture deformation [133]. Miljkovi et al. explored the effect of cationic surfactant dosage on the cement hydration as well as the overall mechanical properties of bitumen emulsion on the mortar scale. The surfactant exerted a significant influence on water binding, cement hydration kinetics, and emulsion rheology characteristics. According to the findings of this study, surfactant dosage may be useful in understanding the mechanical performance of cold 
recycled mixtures [134]. In addition, Ouyang et al. [101] studied the surfactant dosage as well as other formulation parameters. They also investigate how surfactant dosage affects viscosity and an emulsion's ability to penetrate an aggregate base for a prime coat application. It was concluded that emulsions with a high surfactant content were preferred for use in prime coats due to their ability to penetrate effectively into the aggregate base. The $\mathrm{pH}$ of the aqueous phase has also been a major focus of study [101]. Xiao and Jiang [135] identified the effect of $\mathrm{pH}$ values on the physical properties of the resulting emulsion, such as sieve amount, viscosity, residue ductility, residue penetration, and residue softening point, as well as the emulsion's storage stability. While each surfactant has a different optimum $\mathrm{pH}$ value, they concluded that adjusting the $\mathrm{pH}$ of the aqueous phase would have a significant impact on the emulsion's residual amount on the sieve, viscosity, storage stability, and ductility of the residue.

Table 2. Summary of Studies on bitumen emulsion formulation parameters

\begin{tabular}{|c|c|c|}
\hline Study & Variable & Conclusion \\
\hline Pang et al. [133] & surfactant dosage & $\begin{array}{l}\text { Upsurging the surfactant dosage increases the viscosity of } \\
\text { the emulsion. }\end{array}$ \\
\hline $\begin{array}{l}\text { Miljković et al. } \\
\text { [134] }\end{array}$ & $\begin{array}{l}\text { Cationic surfactant dos- } \\
\text { age }\end{array}$ & $\begin{array}{l}\text { The surfactant content affects the cement hydration kinetics, } \\
\text { emulsion rheology, and water binding which are linked to } \\
\text { mechanical performance cold mix. }\end{array}$ \\
\hline Ouyang et al. [101] & surfactant dosage & $\begin{array}{l}\text { More surfactant in prime coat emulsion resulted in en- } \\
\text { hanced penetration into the aggregate base. }\end{array}$ \\
\hline $\begin{array}{c}\text { Xiao and Jiang } \\
\text { [135] }\end{array}$ & $\begin{array}{l}\text { the } \mathrm{pH} \text { of the soap solu- } \\
\text { tion }\end{array}$ & $\begin{array}{l}\text { Different surfactants seem to have an optimal } \mathrm{pH} \text { that affects } \\
\text { the resulting final emulsion properties. }\end{array}$ \\
\hline Cui and Pang [136] & $\begin{array}{l}\text { The } \mathrm{pH} \text { of the soap solu- } \\
\text { tion }\end{array}$ & $\begin{array}{c}\text { The interfacial tension property is dependent on the } \mathrm{pH} \\
\text { value. }\end{array}$ \\
\hline Boucard et al. [137] & Electrolyte Type & $\begin{array}{l}\text { The addition of an electrolyte promotes flocculation, while } \\
\text { the most electrolyte, } \mathrm{NaOH} \text {, promotes coalescence regard- } \\
\text { less of the dispersed phase (bitumen or silicone oil). }\end{array}$ \\
\hline Baumgardner, [98] & Ionic exchange & $\begin{array}{l}\text { Ion exchange should take place enabling the emulsion to re- } \\
\text { tain its properties. }\end{array}$ \\
\hline Baumgardner, [98] & Colloid mill parameters & $\begin{array}{c}\text { Fabrication temperatures, mill speed, residence time, and } \\
\text { mill gap can all have a significant impact on the properties } \\
\text { of bitumen emulsions. }\end{array}$ \\
\hline Kong et al. [138] & $\begin{array}{l}\text { Anionic surfactant Struc- } \\
\text { ture }\end{array}$ & $\begin{array}{l}\text { During the mass transfer process, the SDBS and its isomers } \\
\text { were adsorbed on the calcium carbonate surface and pro- } \\
\text { duced an aggregate structure. Na ions exhibit no evident ag- } \\
\text { gregation behavior in the surfactant's polar head during this } \\
\text { phase. }\end{array}$ \\
\hline Ziari et al. [139] & $\begin{array}{l}\text { Surfactant type and emul- } \\
\text { sification method }\end{array}$ & $\begin{array}{l}\text { The surfactant type and manufacturing technique seemed to } \\
\text { have an impact on the mechanical characteristics of the mix, } \\
\text { such as permanent deformation performance at elevated } \\
\text { temperatures, fatigue cracking performance at intermediate } \\
\text { temperatures, and some other mechanical properties. }\end{array}$ \\
\hline Tan et al. [87]. & $\begin{array}{l}\text { Surfactant type and its } \\
\text { dosages }\end{array}$ & $\begin{array}{l}\text { The surfactant has a considerable retarding impact on ce- } \\
\text { ment hydration, which is related to the surfactant kinds and } \\
\text { doses. }\end{array}$ \\
\hline
\end{tabular}

It was ascertained that the $\mathrm{pH}$ has a direct influence on the surfactant's ability to disperse. This, in turn, affected the bitumen's ability to emulsify and remain stable [135]. Cui and Pang [136] came to an agreement with Xiao and Jiang's conclusion that optimizing the $\mathrm{pH}$ of the soap solution results in improved emulsion stability and performance. Nev- 
ertheless, they concluded that a high $\mathrm{pH}$ value resulted in lower interfacial tension, making bitumen emulsification easier [136]. In the presence of different electrolytes, Boucard et al. [137] investigated the performance of oil/water emulsions formulated with various oils with cationic surfactant quaternary ammonium salt. They discovered that the addition of an electrolyte promotes flocculation in all emulsions, with $\mathrm{NaOH}$ being the most electrolyte that promotes coalescence regardless of whether the dispersed phase is bitumen or silicone oil [137].

Water quality and purity have also an impact on emulsion manufacturing prosses. Baumgardner [98] investigated the occurrence of mineral contaminants in water when employed in bitumen emulsions. To reduce mineral contaminants, an ion exchange must take place, with sodium being added to replace the magnesium and calcium ions frequently found in water. If these are not undertaken, the surfactant will lose its emulsifying characteristics owing to undesired chemical interactions with magnesium and calcium [98]. Using molecular dynamics (MD) simulations, Kong et al. [138] studied the mass transfer mechanism of the anionic surfactant sodium dodecyl benzene sulfonate (SDBS) and its four isomers on the solid surface of calcium carbonate, and also the resulting main chemical component of its aggregates. It was found that the SDBS and its isomers could be adsorbed on the calcium carbonate surface in a very short period of time and subsequently form an aggregate structure throughout the mass transfer process. During this stage, there is no evidence of Na ion aggregation in the surfactant's polar head [138].

Ziari et al. [139] assessed the effects of several manufacturing parameters such as milling variables, post-blending, and soap pre-batching as well as the surfactant type on the properties of various modified bitumen emulsions with Styrene-Butadiene Rubber (SBR) latex, including. The results revealed that each kind of surfactant behaved differently in each process of polymer modification. Furthermore, the surfactant type and production technique impacted the mechanical characteristics of the mix, such as permanent deformation performance at high temperatures, fatigue cracking performance at intermediate temperatures, and other mechanical properties [139]. Table 2 summarizes the main results of the literature.

\section{Bitumen Emulsion Formulation Tools}

The bitumen emulsions are manufactured according to pre-established procedures in industrial applications. Therefore, specific formulation tools/theories, have been presented in the literature. The next sections provide a brief overview of the most essential formulation tools, including the Winsor Ratio (R) theory, the Hydrophilic-Lipophilic Balance (HLB), and the Hydrophilic-Lipophilic Deviation (HLD) approach.

\subsection{The Hydrophilic-Lipophilic Balance (HLB) Concept}

In the last decades, emulsion formulation (particularly bitumen emulsion) has been investigated but not fully understood. Griffin introduced hydrophilic-lipophilic balance (HLB) in 1949, which assigns a surfactant an HLB value that specifies the type of emulsion that surfactant would make. The selection of various surfactants in the emulsification process of bitumen emulsion is commonly still done empirically. Griffin's HLB number [140] is a semi-empirical scale for choosing surfactants. Since then, numerous researchers have sought to establish a quick and reliable procedure for determining the HLB of every new surfactant as a measure of surfactant polarity [141]. The HLB criteria assess whether a surfactant is lipophilic or hydrophilic [142]-[145].

Much research sought to link HLB to various features of surfactant molecules and to improve measuring methods for this parameter [11], [146]-[148]. HLB values of surfactants were first determined through a time-consuming and arduous measurement of emulsion stability [149], particularly for cationic emulsions, for which there is limited information regarding HLB values in the literature. The HLB scale is based on the surfactant molecule's relative fraction of hydrophilic to lipophilic (hydrophobic) groups (s). The HLB is a value ranging from 0 to 20 that reflects how easily a surfactant dissolves in oil or water. HLB equal to 0 corresponds to an entirely hydrophobic (lipophilic) molecule, while a value of 20 corresponds to a molecule consisting entirely of hydrophilic components. The 
hydrophobic chain of an $\mathrm{O} / \mathrm{W}$ emulsion droplet (such as bitumen emulsion) is in the oil phase, while the hydrophilic head group is in the aqueous phase.

The hydrophilic group(s) dwell in the water droplet of a W/O emulsion droplet, whereas the lipophilic groups dwell in the hydrocarbon phase [150]. Table 3 provides guidance in selecting surfactants for a certain application, and Table 4 provides the requisite HLB levels to emulsify various oils. The HLB number is determined by the type of oil. Surfactant HLB values are connected to various other characteristics such as CMC, solubility parameter $(\delta)$, and potential to cause emulsion inversion. The HLB value for nonionic ethoxylated surfactants may be calculated using the following equation (known as Griffin's equation) [151]:

$$
\mathrm{HLB}_{\text {Griffin }}=\frac{1}{5}\left(\frac{\mathrm{M}_{\mathrm{H}}}{\mathrm{M}_{\mathrm{T}}}\right) * 100
$$

where:

$\mathrm{M}_{\mathrm{H}}$ : the molecular mass of the hydrophilic part of the surfactant molecule

Мт: the total molecular mass of the surfactant molecule.

The HLB values, on the other hand, may be derived from their chemical formulas based on group numbers as illustrated in equation 4 based on Davies [152]:

$$
\begin{gathered}
\left.\mathrm{HLB}_{\text {Davies }}=7+\sum \text { (hydrophilic group numbers }\right)- \\
\left.\sum \text { (lipophilic group numbers }\right)
\end{gathered}
$$

The following equation can be used to calculate the HLB value in the case of a surfactant having $\mathrm{n}-\mathrm{CH} 2$-roups:

$$
\begin{aligned}
& \text { HLB } \left._{\text {Davies }}=7+\sum \text { (hydrophilic group numbers }\right) \\
& -\mathrm{n} \text { (group number per } \mathrm{CH}_{2} \text { group) }
\end{aligned}
$$

\begin{tabular}{|c|c|}
\hline $\begin{array}{l}\text { HLB } \\
\text { value }\end{array}$ & Property/application \\
\hline $0-3$ & Antifoaming agent \\
\hline $4-6$ & $\begin{array}{l}\text { W/O (water in oil) surfac- } \\
\text { tant }\end{array}$ \\
\hline 7-9 & Wetting agent \\
\hline $8-18$ & $\mathrm{O} / \mathrm{W}$ surfactant \\
\hline $13-15$ & Detergent \\
\hline 10-18 & Hydrotrope or solubilizer \\
\hline
\end{tabular}

$\mathrm{CH} 2$-group number is replaced by 0.475 and the hydrophilic group numbers are obtained from table 5 [152]

Table 3. Relationship between HLB values and the estimated characteristics [153]. 
Table 4. Required HLB numbers to emulsify various oils [107]

\begin{tabular}{ccc} 
Oil & $\begin{array}{c}\text { W/O } \\
\text { emulsion }\end{array}$ & $\begin{array}{c}\text { O/W } \\
\text { emulsion }\end{array}$ \\
\hline Paraffin oil & 4 & 10 \\
Beeswax & 5 & 9 \\
Linolin, anhy- & 8 & 12 \\
drous & & \\
Cyclohexane & - & 15 \\
Toluene & - & 15 \\
Bitumen [154] & $10-13$ & $4-5$ \\
\hline
\end{tabular}

Table 5. HLB group numbers [152]

\begin{tabular}{|c|c|}
\hline Hydrophilic & Group number \\
\hline$-\mathrm{SO} 4-\mathrm{Na}^{+}$ & 38.7 \\
\hline$-\mathrm{COO}-\mathrm{K}^{+}$ & 21.2 \\
\hline$-\mathrm{COO}-\mathrm{Na}^{+}$ & 19.1 \\
\hline N (tertiary amine) & 9.4 \\
\hline Ester (sorbitan ring) & 6.8 \\
\hline Ester (free) & 2.4 \\
\hline$-\mathrm{COOH}$ & 2.1 \\
\hline Hydroxyl (free) & 1.9 \\
\hline -O- & 1.3 \\
\hline Hydroxyl (sorbitan ring) & 0.5 \\
\hline \multicolumn{2}{|l|}{ Lipophilic } \\
\hline $\begin{array}{l}\mathrm{CH}- \\
-\mathrm{CH}_{2-}- \\
\mathrm{CH}_{3}- \\
=\mathrm{CH}-\end{array}$ & -0.475 \\
\hline \multicolumn{2}{|l|}{ Derived } \\
\hline$-(\mathrm{CH} 2-\mathrm{CH} 2-) \mathrm{O}$ & 0.33 \\
\hline$-(\mathrm{CH} 2-\mathrm{CH} 2-\mathrm{CH} 2-\mathrm{O})-$ & -0.15 \\
\hline
\end{tabular}

Based on the HLB method, Al-Sabagh was able to study the formulation of non-ionic bitumen emulsion using non-ionic surfactants (HLB range from 4 to 17.6) aiming to find a relationship between HLB value and the stability of bitumen emulsion. In his study, bitumen emulsions were formulated with individual and some mixtures of surfactants. The highest stability was found to be in the HLB range of 10-13, with 70\% bitumen (dispersed phase). The rheological results revealed that increasing the carbon numbers in the alkyl chain length increases the viscosity and stability of bitumen emulsions, hence slowing the rate of coalescence. However, this method has its downfalls as it poorly accounts for temperature, salinity, and the nature of the oil, and it is also applicable primarily to non-ionic surfactants [154].

\subsection{Winsor's R-ratio}

Winsor [155] proposed a theoretical approach whereby the emulsion formulations might be assigned to a specific variable. This variable refers to the interaction between energies of adsorbed surfactant molecules with the oil and water in the system. It was demonstrated that the characteristics of an equilibrium system were strongly connected to a specific mix of interactions between surfactant, water, and oil. This interaction combination was denoted by the ratio Winsor ratio (R) [155]-[157].

Winsor's R-ratio [155] is a helpful way of understanding the phase behavior of surfactant-oil-water systems. It is stated as follows: 


$$
\mathrm{R}=\frac{\mathrm{A}_{\mathrm{CO}}}{\mathrm{A}_{\mathrm{CW}}}
$$

Where:

Aco: represent the interactions of the surfactant adsorbed at the interface with the oil.

Acw: represent the interactions of the surfactant adsorbed at the interface with the water molecules.

Table 6 shows how the value of $\mathrm{R}$ is interpreted, where $\mathrm{S}$ represents the surfactant, $\mathrm{O}$ refers to the oil, and $\mathrm{W}$ refers to water. The interactions in Table 6 vary when one parameter is changed, for example, raising the salinity reduces the interaction between the surfactant and the water which leads to a reduced ACW. Consequently, the R-ratio would rise, and the microemulsion system will likely migrate from Type I to Type III. In other words, augmenting water salinity will higher the hydrophobicity of the surfactant system and intensify the interaction between the surfactant and oil, raising the R-ratio. This means that greater hydrophilicity surfactants need larger salinity to create appropriate emulsions [157]. Nevertheless, unlike the HLB approach, this method's R ratio could not even be determined numerically, making it impossible to utilize for practical emulsion formulations.

Table 6. Interpretation of R ratio with emulsion systems [157].

\begin{tabular}{ccc} 
Ratio & Interpretation & Emulsion system \\
\hline $\mathrm{R}<1$ & W-S interaction is greater than O-S interaction & Type I \\
$\mathrm{R}>1$ & O-S interaction is greater than W-S interaction & Type II \\
$\mathrm{R}=1$ & W-S and O-S interactions are balanced (optimum formulation) & Type III \\
\hline
\end{tabular}

\subsection{The Phase Inversion Temperature (PIT) Concept}

Shinoda and Saito [158], [159] are the first to introduce the PIT approach, which makes use of the unique ability of non-ionic surfactants. Non-ionic surfactants behave hydrophilically at low temperatures due to the high hydration of the polar head group, which tends to be more soluble in water [160]. As the temperature increases, the polar head group dehydrates, causing it to become lipophilic. The amphiphilic nature of the surfactant is altered to a lipophilic activity, and the surfactant's solubility in water diminishes. In the oil phase, the surfactant becomes more soluble than in the aqueous phase. Nevertheless, Nevertheless, while shifting from hydrophilic to lipophilic nature, it reaches a temperature known as PIT or hydrophilic-lipophilic balance (HLB), at which neither lipophilicity nor hydrophilicity is present [161]. At this stage, the surfactant's solubility in the oil and aqueous phases is about equal, with extremely low interfacial tensions [162][164].

The PIT method uses ultra-low interfacial tensions at the PIT or HLB temperature to facilitate getting very small droplet sizes. Nonetheless, it has been demonstrated that the emulsions are extremely unstable, with a very quick coalescence rate. As a result, Sherman and colleagues proposed using the PIT approach as a fast way for testing emulsion stability, but preferably for short-term stability assessment as this approach was made upon a relatively small number of surfactants and oils [165]-[167].

\subsection{The Cohesive Energy Ratio (CER) Concept}

Beerbower and colleagues [168] presented the Cohesive Energy Ratio (CER) method tried to achieve a design notion that incorporates both the HLB values and Winsor's R theoretical concept. From a conceptual standpoint, it was quite related to Winsor's R, however, the ratio is between the surfactant layer's adhesion energy to the oil phase and the surfactant layer's adhesion energy to the water phase. The cohesion energy between molecules in a pure component system is calculated as follows: 


$$
\delta^{2}=\frac{\Delta H_{V a p}}{v_{L}}
$$

Where the enthalpy of vaporization and the molar volume in the liquid state are denoted by $\Delta H_{V a p}, \backslash n u_{L}$ respectively. Both are quantifiable numbers. $\backslash$ delta donates to the solubility parameter, which is directly related to the intermolecular cohesion forces. In the case of a mixed system, the adhesion forces between the two types of molecules are calculated using London's geometric mean relationship, as illustrated below.

$$
\begin{gathered}
\delta_{\{A A\}}^{2}=\frac{\Delta H_{A V a p}}{v \cdot A_{L}} \\
\delta_{\{B B\}}^{2}=\frac{\Delta H_{B V a p}}{v \cdot B_{L}} \\
\delta_{\{A B\}}^{2}=\delta_{\{A A\}}^{2 \delta_{\{B\}}^{2}}
\end{gathered}
$$

Hundreds of compounds' solubility parameters have been measured and tabulated, and they are widely used in conjunction with the standard solution model. This can be applied to measure the activity component in a mixture and in an individual into two phases. The adhesion between the surfactant and the oil phase was calculated by computing $\backslash$ delt $a_{\{A B\}}^{2}$ term for which A represents the oil phase and B represents the surfactant's lipophilic component, which was assumed to be equivalent to that of a hydrocarbon with the equivalent chain length [169]. The determination of the adhesion energy on the waterside of the contact is challenging due to a lack of experimental data for the hydrophilic group of specific surfactants. Thus, the cohesive energy ratio's final result is erroneous.

\subsection{Hydrophilic-lipophilic deviation (HLD)}

Due to the drawbacks of the HLB concept and Winsor R ratio in calculating the optimum surfactant formulation processes [170]-[175], researchers [93], [176]-[178] proposed a relatively newer approach that's gained significant support is the hydrophilic-lipophilic deviation (HLD). It's an improvement on the HLB system because it includes terms that account for the salinity, temperature, pressure, oil, and alcohol, as well as surfactant's hydrophobicity [157], [179], [180]. HLD is essentially a balance, as shown in Figure 13 and expressed semi empirically in Equation 11, between the salinity of the system, the Equivalent Alkane Carbon Number (EACN), temperature, and the Characteristic Curvature (Cc) of the surfactant. When these terms are balanced (optimum formulation), the HLD is zero, the surfactant interacts with the water and oil phases equally [181], so Type III microemulsions form, or Type IV if using an excessive surfactant, which gives the largest reduction of interfacial tension (ultra-low surface tension) and the largest increase in the solubility. Due to the drawbacks of the HLB approach and the Winsor R ratio in determining the surfactant formulation procedures [170]-[175], researchers [93], [176]-[178] developed a comparatively recent technique, the hydrophilic-lipophilic deviation, which has garnered substantial acceptance (HLD). It's kind of an enhancement on the HLB system by including variables for salinity, temperature, pressure, oil, and alcohol, as well as the hydrophobicity of the surfactant [157], [179], [180]. As demonstrated in Figure 13, HLD is simply a balance between the salinity of the system, the Equivalent Alkane Carbon Number (EACN), temperature, and the Characteristic Curvature (Cc) of the surfactant. When these terms are balanced (optimal formulation), the HLD is zero, the surfactant interacts equally with the water and oil phases [181], and Type III microemulsions form, or Type IV if excessive surfactant is used, which results in the greatest reduction of interfacial tension (ultra-low surface tension) and the greatest increase in solubility. Emulsions may be formed and identified based on HLD results, as seen in Figure 14. When the HLD value is less than zero, the emulsion is oil in water $(\mathrm{O} / \mathrm{W})$, when it is more than zero, it is water in oil (W/O), and zero refers to the ideal formulation (unstable emulsion tend to break extremely fast). 


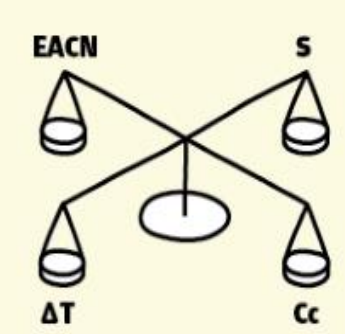

$H L D=S-k . E A C N-a \Delta T+C c$

Figure 13. HLD as a Balancing of System Conditions [182]

The HLD equation's characteristic curvature term is beneficial in defining the hydrophilicity and lipophilicity characteristics of a wide range of surfactants and additives, and also surfactant mixture [183]. HLD-based emulsion formulation has been investigated in a variety of research areas, including enhanced oil recovery and detergent cleaning, drug delivery, and hard surface cleaning [172], [184]. However, there is nearly no research on bitumen emulsion formulation published.

- $\quad$ Electrolyte Type/conc. $[\ln (S)]$

- Surfactant Parameters $\left[C_{c}, a_{T}\right]$

- Oil type [EACN]

- Co-solvent Function $[f(A)]$

- Temperature Coefficient $\left[a_{T}\right]$

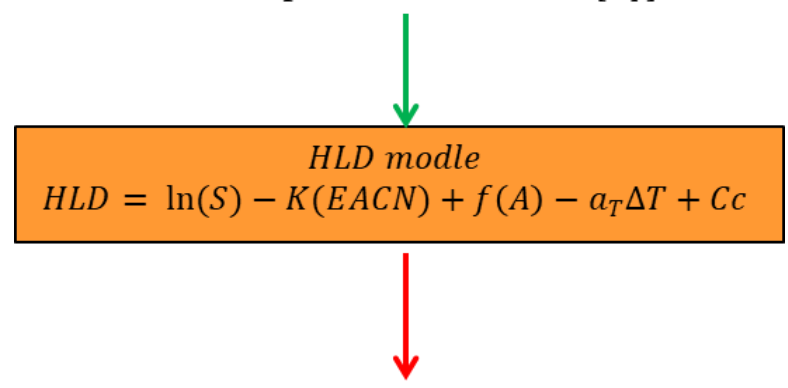

HLD value

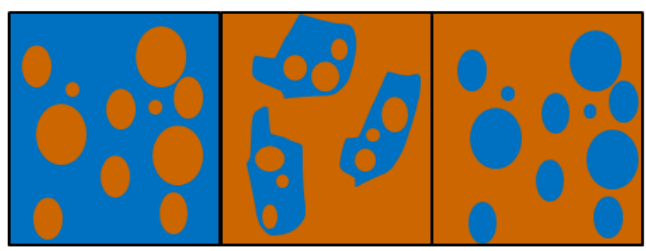

$$
\begin{array}{ccc}
\text { HLD }<0 & \text { HLD }=0 & \text { HLD }>0 \\
\text { o/w } & \text { bicontinuous } & \text { w/o }
\end{array}
$$

Figure 14. Inputs and outputs of HLD equation

$$
H L D=\ln (S)-K(E A C N)+f(A)-a_{T} \Delta T+C c
$$

Where $S^{*}$ is the optimum salinity ( $\mathrm{g} \mathrm{NaCl} / 100 \mathrm{~mL}$ of aqueous phase), $\mathrm{K}$ is a slope of the logarithm of the optimum salinity as a function of EACN, EACN is an equivalent alkane carbon number of the oil, $\mathrm{f}(\mathrm{A})$ is a function of alcohol content which is zero with no alcohol involved, $\mathrm{Cc}$ is a characteristic curvature of the surfactant, $a_{T}$ is a temperature coefficient of optimum salinity, $\mathrm{T}$ is the temperature in ${ }^{\circ} \mathrm{C}$ [185]. 


\subsubsection{Terms characterizing for HLD equation}

The term $\ln (S)$ is responsible for the effect of ionic strength on film curvature. It is presented as a function of the aqueous phase salinity (S) expressed as equivalent grams of $\mathrm{NaCl}$ or HCL (depending on surfactant charge) per $100 \mathrm{~mL}$ [186].

The abbreviation $a_{T} \Delta \mathrm{T}$ describes the influence of temperature variations with regard to the reference temperature $\left(25^{\circ} \mathrm{C}\right)$. Where $a_{T}$ is slightly positive for ionic surfactants (0.01-0.02 for cationic surfactants) and negative for ethoxylated surfactants [187]; and $\Delta \mathrm{T}$ is the temperature difference between the actual and reference temperatures [188]. In order to get the $a_{T}$ value, a graphical relationship between optimal salinity and temperature for a particular surfactant and oil can be used and the arithmetic slope represents the $a_{T}$. In general, the slope values for each anionic, cationic, and non-ionic are, often identical and presumed constant, $0.01,0.02$, and 0.06 respectively [189]. $\mathrm{K}$ is affected by the surfactant's head group [190], [191]. Figure 15 depicts the slope of the observed linear correlation between the logarithm of optimal salinity and the EACN. When all other formulation factors are held constant. The lipophilic interactions between the surfactant's hydrophobic tail and the oil are reflected in K and EACN. K is often dependent on the surfactant family, with values ranging from 0.16 for alkylbenzene sulfonates to 0.10 for fatty acid sodium soaps [192].

Cc is a surfactant characteristic variable that defines the degree to which a surfactant is more hydrophilic or hydrophobic. A hydrophilic surfactant has a negative Cc value, while a hydrophobic surfactant has a positive Cc value. In another word, the Cc parameter describes the surfactant's tendency to cause the interface to curve away from the aqueous phase (hydrophilic surfactant) or away from the oil phase (hydrophobic surfactant). Higher hydrophobic surfactants have a higher positive $C_{c}$ and promote positive HLD [190], [193].

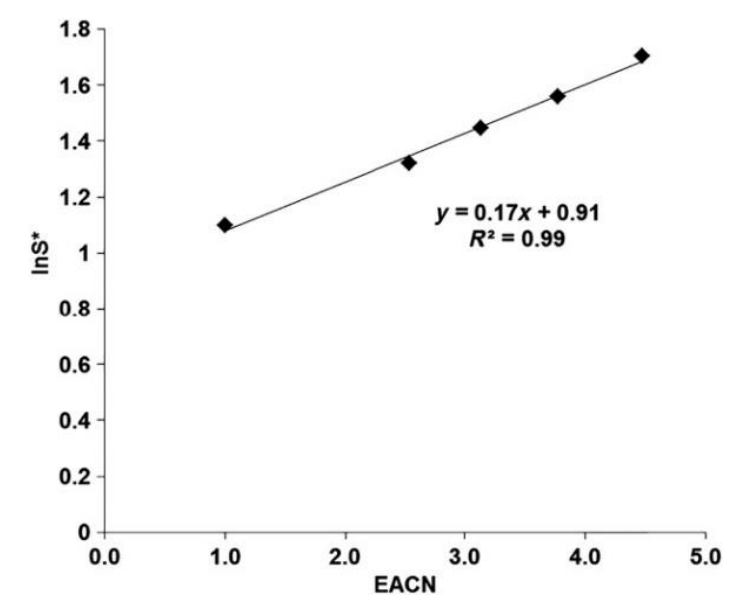

Figure 15. Determining K Constants as Slope [172]

The primary method of determining $\mathrm{Cc}$ is scanning. A scan for an unknown Cc would involve a series of test tubes, the surfactant in question, an oil with known EACN, a salt, and depending on the scan an additional oil with known EACN or surfactant with known Cc. The EACN (equivalent alkane carbon number) is often used to represent the influence of the oil phase and refers to the number of carbon atoms in the case of the linear alkanes. EACN can be established calculated empirically in the case of oil other than n-alkanes (2.5 for bitumen) [194]. $\mathrm{k}$ constant is used in the model to scale the EACN for the reason of getting a reasonable sum with the salinity function.

\subsubsection{HLD emulsion formulation diagram}

HLD has been used frequently to describe regions where emulsions exhibit a given behavior, where they are stable, and where they would invert. Salager et al. [195], graphically represented the HLD values with the emulsion type and inversion line. It is the most important map for describing how to determine an emulsion characteristic needed for a 
certain application. When the formulation is modified or tweaked in relation to the bitumen/aqueous phase composition, a plethora of emulsion types and attributes become available [185]. In Figure 16, the emulsion inversion is depicted by the horizontal line at HLD 0 with the WIII phase behavior in the WOR middle region, i.e., when one of the phases (bitumen/aqueous phase) is less than $70-75$ percent. The normal emulsion $(\mathrm{O} / \mathrm{W}$ or W/O) may be obtained from the diagram where the HLD formulation is in the region of $\mathrm{A}+$ and $\mathrm{A}-$. In the extreme zones, known as $\mathrm{B}+($ or $\mathrm{C}-$ ), which can be thought of as the continuation of the $\mathrm{A}+($ or $\mathrm{A}-$ ) zone with a high dilution. The $\mathrm{B}-$ and $\mathrm{C}+$ zones, on the other hand, are considered to be abnormal because they have multiple emulsions, with droplets in drops creating the internal emulsion and drops in a continuous phase producing the exterior emulsion. The same graphic may be used to predict emulsion fundamental features such as smaller droplets or higher viscosity, as well as stable emulsions [196]. At HLD 0 , there is a very unstable emulsion zone at the horizontal center section of the inversion line which tends to break very fast immediately as soon as it comes into touch with the destabilizer agent (i.e., cement).

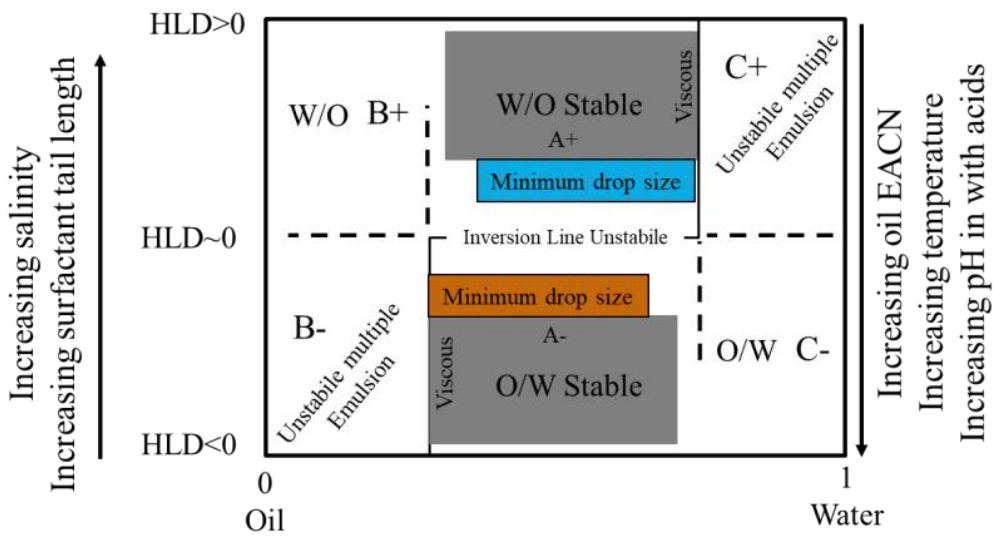

Figure 16. Classical formulation-composition diagram (HLD-WOR) showing the inversion line and emulsion types and the basic properties (stability, drop size, and viscosity) adapted from [195].

\section{Conclusion}

This study summarizes the previous studies aiming to improve knowledge of bitumen emulsion manufacture, its fundamental components, and formulation tools to further maximize the application of cold recycling material technology in practice and rationalize its mix design scientifically. Some techniques have been examined to better engineer the bitumen emulsion properties and make them more user-friendly, cost-effective, and long-lasting alternatives to traditional hot bitumen. Nonetheless, inadequate knowledge on its formulation and complexity can be reflected and identified in unsatisfactory mix design, which can be a serious barrier to a wide range of applications. The study's conclusions are summarized below based on the analysis presented in this paper:

- Although bitumen emulsions are commonly used in road engineering (cold recycling materials), the relevance of the physicochemical formulation of surfactant-bitumenwater systems is still insufficiently known. The effect of formulation and compositional parameters on viscosity, stability droplet size, and distribution has been studied. This is indeed useful not only to predict the bitumen emulsion during mixing and compaction but also to have an indication about the material behavior and rheology during its life.

- Bitumen emulsification processes were identified as a colloid mill and High Internal Phase Ratio (HIPR). Emulsions produced using the colloid mill technique contain a residual bitumen content of up to $70 \%$ by weight, an average droplet size of roughly $5 \mu \mathrm{m}$, and a strong polydispersity. The HIPR approach, on the other hand, may produce within concentrated droplets with an average droplet size of $1 \mu \mathrm{m}$. 
- When a surfactant has been chosen for a specific formulation, the viscosity of the emulsion may be reduced by altering numerous parameters such as increasing WOR, using a lower mill speed, and or offsetting the salinity of the soap phase (if the system is far from the optimal formulation) or even adopting the HIPR method.

- Improving the interfacial contact between bitumen emulsion and mineral aggregate might be aided by optimizing bitumen emulsion production parameters. Because bitumen binder adsorption on the aggregate surface is affected not only by the physical attributes of the aggregate surface but also by the chemical nature of the surfactant.

- When utilizing fatty acids or amine ionic surfactants, formulation acidity dependence is a critical parameter to consider (using $\mathrm{HCl}$ or $\mathrm{NaCl}$ for soap preparation).

- Various formulation tools were presented and reviewed. HLD could be used to formulate and analyze the bitumen emulsification process, as well as anticipate the resulting emulsion characteristics, which can offer an insight into pavement performance to the mix designer. This can be helpful to use the ultimate potential of bitumen emulsion.

There is still an edge for more inventive research since there is no doubt that the commonly employed random trial and error processes for producing bitumen emulsion are destined to fail due to the vast number of variables. One of the goals of this study was to persuade the reader that a large number of know-hows does exit in an easy-organized review, which could be useful to carry out bitumen emulsion formulation engineering tasks for future work.

Author Contributions: Conceptualization, A.A. and K.M.; methodology, A.A..; investigation, A.A.; writing-original draft preparation, A.A.; writing-review and editing, A.A.; visualization, A.A.; supervision, K.M.; project administration, K.M.; funding acquisition, K.M.

Funding: This research was funded by the German Academic Exchange Service (DAAD).

Conflicts of Interest: The authors declare no conflict of interest

\section{Reference}

1. A. F. Nikolaides, “Bituminous Mixtures \& Pavements VI," 2015, doi: 10.1201/b18538.

2. F. Autelitano and F. Giuliani, “Analytical assessment of asphalt odor patterns in hot mix asphalt production," J. Clean. Prod., vol. 172, pp. 1212-1223, 2018.

3. J. P. Gingras, P. A. Tanguy, S. Mariotti, and P. Chaverot, "Effect of process parameters on bitumen emulsions," Chem. Eng. Process. Process Intensif., 2005, doi: 10.1016/j.cep.2005.01.003.

4. J. Read and D. Whiteoak, "The Shell bitumen handbook," Read, J., \& Whiteoak, D. (2003). The Shell bitumen handbook. Thomas Telford. 2003, doi: 10.1680/sbh.32200.

5. A. James, “Overview of asphalt emulsion,” Transp. Res. Circ. E-C102 Asph. Emuls. Technol., pp. 1-15, 2006.

6. M. J. Brennan and C. A. O’Flaherty, "Materials used in road pavements," This B. is Dedic. to Teena O'Flaherty Eva Wallis, p. $118,2002$.

7. R. N. Hunter, Bituminous mixtures in road construction. Thomas Telford, 1994.

8. W. C. Simpson, R. L. Griffin, and T. K. Miles, "Relationship of asphalt properties to chemical constitution," J. Chem. Eng. Data, vol. 6, no. 3, pp. 426-429, 1961.

9. R. B. Girdler, “Constitution of asphaltenes and related studies,” 1965.

10. M. Salou, B. Siffert, and A. Jada, "Interfacial characteristics of petroleum bitumens in contact with acid water," Fuel, vol. 77, no. 4, pp. 343-346, 1998.

11. A. M. Al-Sabagh, N. N. Zaki, and A. M. Badawi, “Effect of binary surfactant mixtures on the stability of asphalt emulsions," J. Chem. Technol. Biotechnol. Int. Res. Process. Environ. Clean Technol., vol. 69, no. 3, pp. 350-356, 1997.

12. X. Lu, P. Sjövall, and H. Soenen, "Structural and chemical analysis of bitumen using time-of-flight secondary ion mass spectrometry (TOF-SIMS)," Fuel, vol. 199, pp. 206-218, Jul. 2017, doi: 10.1016/J.FUEL.2017.02.090.

13. D. Lesueur, "The colloidal structure of bitumen: Consequences on the rheology and on the mechanisms of bitumen modification," Adv. Colloid Interface Sci., vol. 145, no. 1-2, pp. 42-82, Jan. 2009, doi: 10.1016/J.CIS.2008.08.011.

14. A. Jada and M. Salou, "Effects of the asphaltene and resin contents of the bitumens on the water-bitumen interface properties," J. Pet. Sci. Eng., vol. 33, no. 1-3, pp. 185-193, 2002.

15. L. W. Corbett, “Composition of asphalt based on generic fractionation, using solvent deasphaltening, elution-adsorption chromatography, and densimetric characterization," Anal. Chem., vol. 41, no. 4, pp. 576-579, 1969. 
16. Sleem-ur-Rahman and M. C. Dwivedi, "Preparation of anionic asphalt emulsion by partial sulphonation," Pet. Sci. Technol., vol. 15, no. 7-8, pp. 715-727, 1997.

17. J. M. Gibb, “Evaluation of resistance to permanent in the design of bituminous mixtures," The University of Nottingham, 1996.

18. J. Sjoblom, “Emulsions and Emulsion Stability: Surfactant Science Series/61," CRC Press, 2005, doi: 10.1016/0300-9572(85)900152.

19. D. Myers, Surfactant science and technology. John Wiley \& Sons, 2020.

20. M. Salou, B. Siffert, and A. Jada, "Study of the stability of bitumen emulsions by application of DLVO theory," Colloids Surfaces A Physicochem. Eng. Asp., vol. 142, no. 1, pp. 9-16, 1998.

21. P. Schilling, “Emulsifiers for bituminous emulsions." Google Patents, Oct. 15, 1985.

22. S. Ignatavicius, A. Kavanagh, D. Colleran, M. Brennan, and S. Newell, "The use Anionic Bitumen Emulsions in Pavements-A state of the art review," 2021.

23. P. Schilling and E. Crews, "Anionic bituminous emulsions with improved adhesion." Google Patents, Jun. $30,1998$.

24. P. Schilling and H. G. Schreuders, "Viscosifiers for asphalt emulsions," 4859245, Aug. 22, 1989.

25. R. R. Egan, “The preparation and properties of amines and cationic surfactants from fatty acids," J. Am. Oil Chem. Soc., vol. 45, no. 7, pp. 481-486, 1968.

26. DIN EN, “13808, Bitumen and bituminous binders,” Framew. Specif. cationic Bitum. Emuls., vol. 48, 2013.

27. TL BE-StB 15, “Technische Lieferbedingungen für Bitumenemulsionen TL BE-StB 15,” Tech. Regelwerke FGSV-Nr. 793, 2015, Accessed: Dec. 04, 2021. [Online]. Available: https://www.fgsv-verlag.de/tl-be-stb.

28. P. K. Kilpatrick, “Water-in-Crude Oil Emulsion Stabilization: Review and Unanswered Questions," Energy and Fuels, vol. 26, no. 7, pp. 4017-4026, Jul. 2012, doi: 10.1021/EF3003262.

29. D. Schuster, Encyclopedia of emulsion technology. 1996.

30. A. Braham, "Introduction to asphalt emulsions (certificate 1)," Pavement Maint. Rehabil. Prof. Dev. Courses, Univ. Arkansas, Fayetteville, AR, USA, 2017.

31. J. Sjoblom, “Encyclopedic handbook of emulsion technology," p. 736, 2001, Accessed: Jul. 07, 2021. [Online]. Available: https://books.google.com/books/about/Encyclopedic_Handbook_of_Emulsion_Techno.html?hl=de\&id=Q4wwWbQTivUC.

32. G. Urbina-Villalba, "An algorithm for emulsion stability simulations: Account of flocculation, coalescence, surfactant adsorption and the process of ostwald ripening," Int. J. Mol. Sci., vol. 10, no. 3, pp. 761-804, Mar. 2009, doi: 10.3390/IJMS10030761.

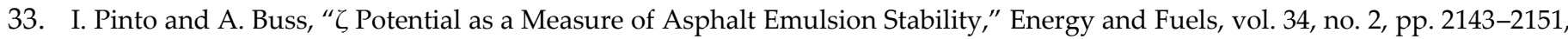
Feb. 2020, doi: 10.1021/acs.energyfuels.9b03565.

34. S. Furlong, A. James, E. Kalinowski, and M. Thompson, "Water enclosed within the droplets of bitumen emulsions and its relation to viscosity changes during storage," Colloids Surfaces A Physicochem. Eng. Asp., vol. 152, no. 1-2, pp. 147-153, 1999.

35. K. BOUSSAD, C. LASSEUR, and B. LOMBARDI, "2-LES OUTILS PROPOSES PAR LES ENTREPRISES-LA DISTRIBUTION GRANULOMETRIQUE DES EMULSIONS DE BITUME: UN PARAMETRE CLE POUR AJUSTER LEUR VISCOSITE," Rev. Gen. DES ROUTES DES AERODROMES, no. HS1, 1995.

36. P. Sherman, "Industrial rheology with particular reference to foods, pharmaceuticals, and cosmetics.," Ind. Rheol. with Part. Ref. to foods, Pharm. Cosmet., 1970.

37. D. Lesueur, M. Ezzarougui, G. Hervé, and L. Odie, “The Rheological Properties of Bitumen Emulsions Part II-Experimental Characterization," Road Mater. pavement Des., vol. 4, no. 2, pp. 169-184, 2003.

38. R. J. M. Tausk and P. N. Wilson, "Colloid chemical studies on bitumen-in-water emulsions part I. absorption of water in the bitumen droplets and other factors affecting emulsion viscosity," Colloids and Surfaces, vol. 2, no. 1, pp. 71-80, 1981.

39. J.-P. P. Gingras et al., "Effect of process parameters on bitumen emulsions," Chem. Eng. Process. Process Intensif., vol. 44, pp. 979-986, 2005, doi: 10.1016/j.cep.2005.01.003.

40. M. Rámirez, J. Bullón, J. Andérez, I. Mira, and J.-L. Salager, “Drop size distribution bimodality and its effect on O/W emulsion viscosity," J. Dispers. Sci. Technol., vol. 23, no. 1-3, pp. 309-321, 2002.

41. O. S. Alade et al., "Experimental and numerical studies on production scheme to improve energy efficiency of bitumen production through insitu oil-in-water (O/W) emulsion," Energy, p. 122700, 2021.

42. J. L. Salager et al., "Surfactant-oil-water systems near the affinity inversion part II: viscosity of emulsified systems," J. Dispers. Sci. ANDTECHNOLOGY, vol. 4, no. 2, pp. 161-173, 1983.

43. J. Samanos, "Method for preparing a bitumen emulsion, corresponding bitumen emulsion and use thereof." Google Patents, Jun. 10, 2003.

44. J. L. Gorman, R. J. Crawford, P. Stannard, and I. H. Harding, "The role of aggregate surface chemistry in bitumen emulsion-aggregate interactions," Road Transp. Res., vol. 7, no. 4, p. 3, 1998.

45. A. P. Hagen, W. D. Lee, and T. M. Jones, "Asphalt-aggregate interactions characterized by zeta potential and retained strength measurements for natural and organosilane-treated aggregates," Transp. Res. Rec., vol. 1535, no. 1, pp. 111-116, 1996.

46. J. Lyklema, "Adsorption at solid-liquid interfaces with special reference to emulsion systems," Colloids Surfaces A Physicochem. Eng. Asp., vol. 91, no. C, pp. 25-38, Nov. 1994, doi: 10.1016/0927-7757(94)02718-8.

47. G. L. Castillo, P. A. J. Poirier, and M. Bourrell, "Breaking of an asphalt emulsion on a mineral aggregate: phenomenology, modelling and optimization," in Proceedings of the First World Congress on Emulsion, Paris, France, 1993, pp. 19-22. 
48. M. A. Rodríguez-Valverde, P. Ramón-Torregrosa, A. Páez-Dueñas, M. A. Cabrerizo-Vílchez, and R. Hidalgo-Álvarez, Imaging techniques applied to characterize bitumen and bituminous emulsions, vol. 136, no. 1-2. Elsevier, 2008, pp. 93-108.

49. D. Needham, "Developments in bitumen emulsion mixtures for roads," 1996. [Online]. Available: http://eprints.nottingham.ac.uk/11101/.

50. I. N. A. Thanaya, "IMPROVING THE PERFORMANCE EMULSION OF COLD BITUMINOUS ( CBEMs ) INCORPORATING WASTE The University of Leeds School of Civil Engineering," no. July, 2003.

51. J. E. Poirier, M. Bourrel, P. Castillo, C. Chambu, and M. Kbala, "Asphalt emulsions: experimental study of the cationic surfactant adsorption at the asphalt-water interface," Trends colloid interface Sci. III, pp. 106-111, 1989.

52. T. Saadoon, A. Garcia, and B. Gómez-Meijide, "Dynamics of water evaporation in cold asphalt mixtures," Mater. Des., 2017, doi: 10.1016/j.matdes.2017.08.040.

53. A. Al-Mohammedawi and K. Mollenhauer, "A Study on the Influence of the Chemical Nature of Fillers on Rheological and Fatigue Behavior of Bitumen Emulsion Mastic," Mater. 2020, Vol. 13, Page 4627, vol. 13, no. 20, p. 4627, Oct. 2020, doi: 10.3390/MA13204627.

54. S. Shekhovtsova, A. Korotkov, and M. Vysotskaya, "Method of forecasting the effectiveness of cationic bitumen emulsions," Mag. Civ. Eng., vol. 78, no. 2, pp. 91-100, 2018, doi: 10.18720/MCE.78.7.

55. F. Tang, G. Xu, T. Ma, and L. Kong, "Study on the Effect of Demulsification Speed of Emulsified Asphalt based on Surface Characteristics of Aggregates," Mater. 2018, Vol. 11, Page 1488, vol. 11, no. 9, p. 1488, Aug. 2018, doi: 10.3390/MA11091488.

56. D. Shaw, Introduction to colloid and surface chemistry. 1992.

57. N. Izzi, M. Yusoff, E. Chailleux, and G. D. Airey, “A Comparative Study of the Influence of Shift Factor Equations on Master Curve Construction," ISSN Int. J. Pavement Res. Technol. Int. J. Pavement Res. Technol., vol. 44, no. 66, pp. 324-336, 1997, [Online]. Available: http://www.ijprt.org.tw/mailweb/files/sample/V4N6_324-336.pdf.

58. H. Shi, T. Xu, and R. Jiang, “Combustion mechanism of four components separated from asphalt binder,” Fuel, vol. 192, pp. 1826, Mar. 2017, doi: 10.1016/J.FUEL.2016.11.110.

59. E. R. Brown, P. S. Kandhal, F. L. Roberts, Y. R. Kim, D.-Y. Lee, and T. W. Kennedy, Hot mix asphalt materials, mixture design, and construction. NAPA research and education foundation, 2009.

60. P. T. Johannes, "Development of an improved mixture design framework for slurry seals and micro-surfacing treatments." The University of Wisconsin-Madison, 2014.

61. L. Kong et al., "Exploration of molecular dynamics for the adsorption of anionic emulsifier on the main chemical composition surface of aggregate," Constr. Build. Mater., vol. 292, p. 123210, 2021.

62. S.-G. Hu, T. Wang, F.-Z. Wang, and Z.-C. Liu, “Adsorption behaviour between cement and asphalt emulsion in cement-asphalt mortar," http://dx.doi.org/10.1680/adcr.2007.00034, vol. 21, no. 1, pp. 11-14, May 2015, doi: 10.1680/ADCR.2007.00034.

63. L. Loeber, G. Mueller, B. Héritier, T. Jolivet, and M. Malot, "An attempt to the understanding on the mechanism of film formation of a bituminous emulsion on mineral substrate," $2^{\wedge}\{\mathrm{nd}\}$ Eurasphalt Eurobitume Congr., 2000, Accessed: Jul. 07, 2021. [Online]. Available: https://trid.trb.org/view/674031.

64. R. Micaelo, A. Guerra, L. Quaresma, and M. T. Cidade, "Study of the effect of filler on the fatigue behaviour of bitumen-filler mastics under DSR testing," Constr. Build. Mater., vol. 155, pp. 228-238, 2017, doi: 10.1016/j.conbuildmat.2017.08.066.

65. X. Wu, J. Czarnecki, N. Hamza, and J. Masliyah, “Interaction Forces Between Bitumen Droplets in Water," Langmuir, vol. 15, no. 16, pp. 5244-5250, Aug. 1999, doi: 10.1021/la981546q.

66. L. I, W. X, M. JH, and C. J, “Dynamic and static interactions between bitumen droplets in water," J. Colloid Interface Sci., vol. 250, no. 2, pp. 316-326, 2002, doi: 10.1006/JCIS.2002.8369.

67. J. Liu, Z. Xu, and J. Masliyah, “Colloidal forces between bitumen surfaces in aqueous solutions measured with atomic force microscope," Colloids Surfaces A Physicochem. Eng. Asp., vol. 260, no. 1-3, pp. 217-228, 2005.

68. J. Liu, Z. Zhou, Z. Xu, and J. Masliyah, "Bitumen-clay interactions in aqueous media studied by zeta potential distribution measurement," J. Colloid Interface Sci., vol. 252, no. 2, pp. 409-418, 2002.

69. J. Liu, Z. Xu, and J. Masliyah, "Studies on bitumen- silica interaction in aqueous solutions by atomic force microscopy," Langmuir, vol. 19, no. 9, pp. 3911-3920, 2003.

70. J. Liu, Z. Xu, and J. Masliyah, "Interaction between bitumen and fines in oil sands extraction system: Implication to bitumen recovery," Can. J. Chem. Eng., vol. 82, no. 4, pp. 655-666, 2004.

71. J. Long, Z. Xu, and J. H. Masliyah, "Adhesion of single polyelectrolyte molecules on silica, mica, and bitumen surfaces," Langmuir, vol. 22, no. 4, pp. 1652-1659, 2006.

72. H. Zhao, J. Long, J. H. Masliyah, and Z. Xu, "Effect of divalent cations and surfactants on silica- bitumen interactions," Ind. Eng. Chem. Res., vol. 45, no. 22, pp. 7482-7490, 2006.

73. J. Long, L. Zhang, Z. Xu, and J. H. Masliyah, “Colloidal interactions between Langmuir- Blodgett bitumen films and fine solid particles," Langmuir, vol. 22, no. 21, pp. 8831-8839, 2006.

74. U. Isacsson, "A compilation of laboratory methods for studying stability of bitumen emulsions," Mater. Struct., vol. 18, no. 3, pp. 228-236, 1985.

75. E. K. Ensley, J. C. Petersen, and R. E. Robertson, “Asphalt-aggregate bonding energy measurements by microcalorimetric methods," Thermochim. Acta, vol. 77, no. 1-3, pp. 95-107, 1984. 
76. D. V. Nowell and M. W. Powell, "Determination of adhesion in bitumen-mineral systems by heat-of-immersion calorimetry," J. Therm. Anal., vol. 37, no. 9, pp. 2109-2124, Sep. 1991, doi: 10.1007/BF01905582.

77. J. M. Letoffe, P. Claudy, J. P. Planche, and L. Germanaud, “CHARACTERIZATION OF BITUMEN-AGGREGATE INTERACTION BY ISOTHERMAL MICROCALORIMETRY," Thermochim. Acta, vol. 210, pp. 27-40, 1992.

78. M. B. Evans, D. V. Nowell, and M. W. Powell, "Determination of adhesion in bitumenmineral systems by heat-of-immersion calorimetry," J. Therm. Anal. 1993 401, vol. 40, no. 1, pp. 121-131, Feb. 2014, doi: 10.1007/BF02546562.

79. J. R. Lu et al., "The composition and structure of sodium dodecyl sulfate-dodecanol mixtures adsorbed at the air-water interface: a neutron reflection study," J. Colloid Interface Sci., vol. 174, no. 2, pp. 441-455, 1995.

80. J. C. Conboy, M. C. Messmer, and G. L. Richmond, "Effect of alkyl chain length on the conformation and order of simple ionic surfactants adsorbed at the D2O/CCl4 interface as studied by sum-frequency vibrational spectroscopy," Langmuir, vol. 14, no. 23, pp. 6722-6727, 1998.

81. H. Kunieda, K. Ozawa, K. Aramaki, A. Nakano, and C. Solans, "Formation of microemulsions in mixed ionic- nonionic surfactant systems," Langmuir, vol. 14, no. 2, pp. 260-263, 1998.

82. J. Penfold et al., "Structure and composition of the mixed monolayer of hexadecyltrimethylammonium bromide and benzyl alcohol adsorbed at the air/water interface," Langmuir, vol. 14, no. 8, pp. 2139-2144, 1998.

83. J. Penfold, E. Staples, I. Tucker, L. Soubiran, A. Creeth, and J. Hubbard, “Adsorption of di-chain cationic and non-ionic surfactant mixtures at the air/water interface," Phys. Chem. Chem. Phys., vol. 2, no. 22, pp. 5230-5234, 2000.

84. A. Bumajdad et al., "Interfacial compositions and phase structures in mixed surfactant microemulsions," Langmuir, vol. 15, no. 16, pp. 5271-5278, 1999.

85. C. E. McKenna, M. M. Knock, and C. D. Bain, “First-order phase transition in mixed monolayers of hexadecyltrimethylammonium bromide and tetradecane at the air- water interface," Langmuir, vol. 16, no. 14, pp. 5853-5855, 2000.

86. S. R. Jin, K. Zhang, J. X. Pang, and S. S. Song, "Synthesis and application research of op-10/cationic surfactant composite asphalt emulsifier," in Applied Mechanics and Materials, 2013, vol. 364, pp. 664-668, doi: 10.4028/WWW.SCIENTIFIC.NET/AMM.364.664.

87. Y. Tan, J. Ouyang, J. Lv, and Y. Li, “Effect of emulsifier on cement hydration in cement asphalt mortar," Constr. Build. Mater., vol. 47, pp. 159-164, 2013, doi: 10.1016/j.conbuildmat.2013.04.044.

88. W. Heukelom and P. W. Wijga, "Bitumen testing-an introduction to the use of test methods at the Koninklijke/Shell Laboratorium, Amsterdam," 1973.

89. K. Majidzadeh and F. N. Brovold, "Effect of water on bitumen-aggregate mixtures," 1966.

90. A. Baldi-Sevilla, J. P. Aguiar-Moya, A. Vargas-Nordcbeck, and L. Loria-Salazar, “Effect of aggregate-bitumen compatibility on moisture susceptibility of asphalt mixtures," Road Mater. Pavement Des., vol. 18, no. sup2, pp. 318-328, 2017.

91. F. Goodarzi and S. Zendehboudi, "A comprehensive review on emulsions and emulsion stability in chemical and energy industries," Can. J. Chem. Eng., vol. 97, no. 1, pp. 281-309, 2019.

92. A. Gupta, H. B. Eral, T. A. Hatton, and P. S. Doyle, “Nanoemulsions: formation, properties and applications," Soft Matter, vol. 12, no. 11, pp. 2826-2841, 2016.

93. G. Tartaro, H. Mateos, D. Schirone, R. Angelico, and G. Palazzo, “Microemulsion microstructure(s): A tutorial review," Nanomaterials, vol. 10, no. 9, pp. 1-40, 2020, doi: 10.3390/nano10091657.

94. T. F. Tadros, Rheology of dispersions: principles and applications. John Wiley \& Sons, 2011.

95. N. Querol, C. Barreneche, and L. F. Cabeza, "Method for controlling mean droplet size in the manufacture of phase inversion bituminous emulsions," Colloids Surfaces A Physicochem. Eng. Asp., vol. 527, pp. 49-54, 2017.

96. K. Schroën, J. de Ruiter, and C. Berton-Carabin, "The importance of interfacial tension in emulsification: Connecting scaling relations used in large scale preparation with microfluidic measurement methods," ChemEngineering, vol. 4, no. 4, p. 63, 2020.

97. S. Maindarkar, A. Dubbelboer, J. Meuldijk, H. Hoogland, and M. Henson, "Prediction of emulsion drop size distributions in colloid mills," Chem. Eng. Sci., vol. 118, pp. 114-125, 2014.

98. G. L. Baumgardner, “Asphalt emulsion manufacturing today and tomorrow,” Asph. Emuls. Technol., pp. 16-25, 2006.

99. L. You, Q. Dai, Z. You, X. Zhou, and S. Washko, “Stability and rheology of asphalt-emulsion under varying acidic and alkaline levels," J. Clean. Prod., vol. 256, p. 120417, 2020.

100. Z. G. Liu, L. Zong, L. Le Zhao, and X. M. Xie, “Preparation and storage stability of asphalt emulsions made from modified lignin cationic asphalt emulsifiers," in Applied Mechanics and Materials, 2013, vol. 357, pp. 781-785.

101. J. Ouyang, Y. Sun, and S. Zarei, "Fabrication of solvent-free asphalt emulsion prime with high penetrative ability," Constr. Build. Mater., vol. 230, p. 117020, 2020.

102. X. Gutierrez, F. Silva, M. Chirinos, J. Leiva, and H. Rivas, “Bitumen-in-water emulsions: An overview on formation, stability, and rheological properties," J. Dispers. Sci. Technol., 2002, doi: 10.1080/01932690208984213.

103. R. N. Hunter, A. Self, J. Read, and E. Hobson, The shell bitumen handbook. ICE Publishing London, UK:, 2015.

104. J. Kumasaka and R. Ueda, “Effect of Emulsification Process Conditions on the Properties of Water-in-Bitumen Emulsion," J. Japanese Assoc. Pet. Technol., vol. 82, no. 1, pp. 74-84, 2017.

105. J.-M. Dresin, N. Picard, B. Siaud, and C. Stock, "Bitumen emulsions, method for obtaining them and compositions containing same." Google Patents, Sep. 17, 2002.

106. R. V Calabrese, “Assessment of rotor-stator mixing devices,” 1999. 
107. T. F. Tadros, “Emulsion Formation, Stability, and Rheology," in Emulsion Formation and Stability, 2013.

108. J.-P. Gingras, P. A. Tanguy, S. Mariotti, and P. Chaverot, "Effect of Process Parameters on Bitumen Emulsions," Chem. Eng. Process. Process Intensif., vol. 44, pp. 979-986, 2005, doi: 10.1016/j.cep.2005.01.003.

109. A. Institute and A. E. M. Association, A basic asphalt emulsion manual, Manual Ser. Lexington: Department of Transportation, Federal Highway Administration, 1997.

110. G. Hooleran, “Analysis of emulsion stability and asphalt compatibility," 1999.

111. K. J. Lissant and K. G. Mayhan, “A study of medium and high internal phase ratio water/polymer emulsions,” J. Colloid Interface Sci., vol. 42, no. 1, pp. 201-208, 1973.

112. K. J. Lissant, “Emulsions and emulsion technology," Soil Sci., vol. 120, no. 2, p. 160, 1975.

113. D. Lesueur, L. Herrero, J. Hurtado, J. J. Potti, and M. A. Rodríguez-Valverde, “Taylor-made bitumen emulsions manufacturing using the High Internal Phase Ratio method," in 4th World Congress on Emulsion, 2006, vol. 475.

114. M. P. Aronson and M. F. Petko, “High internal phase emulsions.” Google Patents, Aug. 19, 1986.

115. J.-P. Gingras, L. Fradette, P. Tanguy, and E. Jorda, “Concentrated bitumen-in-water emulsification in coaxial mixers,” Ind. Eng. Chem. Res., vol. 46, no. 6, pp. 1818-1825, 2007.

116. H. Rivas, F. Silva, X. Gutierrez, and G. Nunez, "Bitumen in water bimodal emulsions stabilized by natural surfactants," J. Dispers. Sci. Technol, vol. 23, pp. 405-418, 2002.

117. N. Querol, C. Barreneche, and L. F. Cabeza, “Storage stability of bimodal emulsions vs. monomodal emulsions,” Appl. Sci., vol. 7, no. 12, p. 1267, 2017.

118. E. Arenas-Calderon, V. Sadtler, P. Marchal, L. Choplin, F. Delfosse, and M. Maze, "Preparation of highly concentrated bitumen emulsions by catastrophic phase inversion: Follow-up of the emulsification process," Colloids Surfaces A Physicochem. Eng. Asp., vol. 458, pp. 25-31, Feb. 2014, doi: 10.1016/j.colsurfa.2014.02.030.

119. C. Dicharry, J. Diaz, J.-P. Torré, and M. Ricaurte, "Influence of the carbon chain length of a sulfate-based surfactant on the formation of CO2, CH4 and CO2-CH4 gas hydrates," Chem. Eng. Sci., vol. 152, pp. 736-745, 2016.

120. S. Dölle, B. Lechner, J. H. Park, S. Schymura, J. P. F. Lagerwall, and G. Scalia, “Utilizing the Krafft Phenomenon to Generate Ideal Micelle-Free Surfactant-Stabilized Nanoparticle Suspensions," Angew. Chemie Int. Ed., vol. 51, no. 13, pp. 3254-3257, 2012.

121. F. Makavipour, R. M. Pashley, and A. F. M. M. Rahman, “Low-Level Arsenic Removal from Drinking Water,” Glob. Challenges, vol. 3, no. 3, p. 1700047, 2019.

122. T. L. Moon, M. Blanzat, L. Labadie, E. Perez, and I. Rico-Lattes, “Synthesis and physicochemical study of new surfactants derived from carboxylic acid sugars," J. Dispers. Sci. Technol., vol. 22, no. 2-3, pp. 167-176, 2001.

123. N. A. Malik and A. Ali, "Krafft temperature and thermodynamic study of interaction of glycine, diglycine, and triglycine with hexadecylpyridinium chloride and hexadecylpyridinium bromide: a conductometric approach," J. Mol. Liq., vol. 213, pp. 213220, 2016.

124. H. Kunieda and K. Shinoda, "Krafft points, critical micelle concentrations, surface tension, and solubilizing power of aqueous solutions of fluorinated surfactants," J. Phys. Chem., vol. 80, no. 22, pp. 2468-2470, 1976.

125. M. N. Islam, K. K. Sharker, and K. C. Sarker, "Salt-induced modulation of the Krafft temperature and critical micelle concentration of benzyldimethylhexadecylammonium chloride," J. Surfactants Deterg., vol. 18, no. 4, pp. 651-659, 2015.

126. J. C. Roy, M. N. Islam, and G. Aktaruzzaman, "The effect of $\mathrm{NaCl}$ on the Krafft temperature and related behavior of cetyltrimethylammonium bromide in aqueous solution," J. Surfactants Deterg., vol. 17, no. 2, pp. 231-242, 2014.

127. D. Lesueur, "Polymer modified bitumen emulsions (PMBEs)," in Polymer modified bitumen, Elsevier, 2011 , pp. 25-42.

128. A. M. M. Abd El-Rahman, M. El-Shafie, Z. L. Abo-Shanab, and S. A. El-Kholy, “Modifying asphalt emulsion with different types of polymers for surface treatment applications," Pet. Sci. Technol., vol. 35, no. 14, pp. 1473-1480, 2017.

129. M. A. Shafii, M. Y. A. Rahman, and J. Ahmad, “Polymer modified asphalt emulsion,” 2011.

130. Y.-Q. Yuan, X.-W. Zou, and P.-F. Xiong, “Effects of temperature on the emulsification in surfactant-water-oil systems," Int. J. Mod. Phys. B, vol. 17, no. 14, pp. 2773-2780, 2003.

131. O. Massarweh and A. S. Abushaikha, "The use of surfactants in enhanced oil recovery: A review of recent advances," Energy Reports, vol. 6, pp. 3150-3178, 2020.

132. S. JAMES, Alan; LOGARAJ, "EMULSIFICATION OF HIGH SOFTENING POINT HYDROCARBONS EMULSIFICATION D'HYDROCARBURES A HAUT POINT DE RAMOLLISSEMENT."

133. J. Pang, S. Du, R. Chang, Q. Pei, and D. Cui, "Effect of emulsifier content on the rheological properties of asphalt emulsion residues," J. Appl. Polym. Sci., vol. 132, no. 15, 2015.

134. M. Miljković, M. Radenberg, X. Fang, and P. Lura, “Influence of emulsifier content on cement hydration and mechanical performance of bitumen emulsion mortar," Mater. Struct., vol. 50, no. 3, pp. 1-14, 2017.

135. J. J. Xiao and W. Jiang, "Study the Influence of Soap Solution's pH Value on the Modified Asphalt Emulsion Performance," in Applied Mechanics and Materials, 2013, vol. 253, pp. 312-316.

136. D. Cui and J. Pang, "The effect of ph on the properties of a cationic bitumen emulsifier," Tenside, Surfactants, Deterg., vol. 54, no. 5, pp. 386-392, 2017, doi: 10.3139/113.110520.

137. L. Boucard, V. Schmitt, F. Farcas, and V. Gaudefroy, "Bitumen emulsions formulation and destabilisation process relationship: influence of salts addition," Road Mater. Pavement Des., vol. 16, no. sup1, pp. 330-348, 2015. 
138. L. Kong, W. Luo, B. Feng, and X. Quan, “Influence of emulsifier on surface mass transfer based on molecular dynamics simulations," Front. Mater., vol. 7, p. 1, 2020.

139. H. Ziari, M. R. Keymanesh, and H. Zalnezhad, "Effect of emulsifying agent on rheological properties of bitumen emulsion modified with different techniques of adding SBR latex polymer," Road Mater. Pavement Des., pp. 1-17, 2020.

140. W. C. Griffin, “Classification of surface-active agents by" HLB",” J. Soc. Cosmet. Chem., vol. 1, pp. 311-326, 1949.

141. R. C. Pasquali, N. Sacco, and C. Bregni, "The studies on hydrophilic-lipophilic balance (HLB): Sixty years after William C. Griffin's pioneer work (1949-2009)," Lat Am J Pharm, vol. 28, no. 2, pp. 313-317, 2009.

142. H. Kunieda and K. Shinoda, "Evaluation of the hydrophile-lipophile balance (HLB) of nonionic surfactants. I. Multisurfactant systems," J. Colloid Interface Sci., vol. 107, no. 1, pp. 107-121, 1985.

143. S. S. Reham, H. H. Masjuki, M. A. Kalam, I. Shancita, I. M. R. Fattah, and A. M. Ruhul, “Study on stability, fuel properties, engine combustion, performance and emission characteristics of biofuel emulsion," Renew. Sustain. Energy Rev., vol. 52, pp. 1566-1579, 2015.

144. S. Kondo et al., "Effect of the hydrophilic-lipophilic balance (HLB) of surfactants included in the post-CMP cleaning chemicals on porous SiOC direct CMP," in 2007 IEEE International Interconnect Technology Conferencee, 2007, pp. 172-174.

145. R. C. L. Dryburgh, "The influence of the characteristics of emulsifying agents on the stabilisation of granular materials using nano-silane modified bitumen emulsions."

146. H. Kunieda, "Correlation between the formation of a lamellar liquid crystalline phase and the hydrophile-lipophile balance (HLB) of surfactants," J. Colloid Interface Sci., vol. 114, no. 2, pp. 378-385, 1986.

147. A. M. Al-Sabagh, "The relevance HLB of surfactants on the stability of asphalt emulsion," Colloids Surfaces A Physicochem. Eng. Asp., 2002, doi: 10.1016/S0927-7757(01)01115-3.

148. X. Barril, J. Muñoz, F. J. Luque, and M. Orozco, "Simplified descriptions of the topological distribution of hydrophilic/hydrophobic characteristics of molecules," Phys. Chem. Chem. Phys., vol. 2, no. 21, pp. 4897-4905, 2000.

149. A. NEEDS, "time-saving guide to emulsifier selection," 1976.

150. A. Gadhave, “Determination of hydrophilic-lipophilic balance value,” Int. J. Sci. Res, vol. 3, no. 4, pp. 573-575, 2014.

151. M. Royer, M. Nollet, M. Catte, M. Collinet, and C. Pierlot, "Towards a new universal way to describe the required hydrophilic lipophilic balance of oils using the phase inversion temperature of C10E4/n-octane/water emulsions," Colloids Surfaces A Physicochem. Eng. Asp., vol. 536, pp. 165-171, 2018.

152. J. T. Davies, “A quantitative kinetic theory of emulsion type, I. Physical chemistry of the emulsifying agent," in Gas/Liquid and Liquid/Liquid Interface. Proceedings of the International Congress of Surface Activity, 1957, vol. 1, pp. 426-438.

153. J. J. Sheng, Modern chemical enhanced oil recovery: theory and practice. Gulf Professional Publishing, 2010.

154. R. Marquez, A. M. Forgiarini, J. Fernández, D. Langevin, and J. Salager, "New interfacial rheology characteristics measured using a spinning-drop Rheometer at the optimum formulation of a simple surfactant-oil-water system," J. Surfactants Deterg., vol. 21, no. 5, pp. 611-623, 2018.

155. P. A. Winsor, Solvent properties of amphiphilic compounds. Butterworths Scientific Publications, 1954.

156. T. T. L. Nguyen, A. Edelen, B. Neighbors, and D. A. Sabatini, “Biocompatible lecithin-based microemulsions with rhamnolipid and sophorolipid biosurfactants: formulation and potential applications," J. Colloid Interface Sci., vol. 348, no. 2, pp. 498-504, 2010.

157. J.-L. Salager, R. E. Antón, D. A. Sabatini, J. H. Harwell, E. J. Acosta, and L. I. Tolosa, "Enhancing solubilization in microemulsions - state of the art and current trends," J. Surfactants Deterg., vol. 8, no. 1, pp. 3-21, 2005.

158. H. Arai and K. Shinoda, "The effect of mixing of oils and of nonionic surfactants on the phase inversion temperatures of emulsions," J. Colloid Interface Sci., vol. 25, no. 3, pp. 396-400, 1967.

159. K. Shinoda and H. Saito, "The stability of O/W type emulsions as functions of temperature and the HLB of emulsifiers: the emulsification by PIT-method," J. Colloid Interface Sci., vol. 30, no. 2, pp. 258-263, 1969.

160. T. Tadros, P. Izquierdo, J. Esquena, and C. Solans, “Formation and stability of nano-emulsions," Adv. Colloid Interface Sci., vol. 108, pp. 303-318, 2004.

161. K. Shinoda, "The comparison between the PIT system and the HLB-value system to emulsifier selection," in Proceedings of the 5th International Congress of Surface Activity, 1969, vol. 2, pp. 275-283.

162. D. J. McClements, “Edible nanoemulsions: fabrication, properties, and functional performance," Soft Matter, vol. 7, no. 6, pp. 2297-2316, 2011.

163. C. Solans and I. Solé, "Nano-emulsions: formation by low-energy methods," Curr. Opin. Colloid Interface Sci., vol. 17, no. 5, pp. 246-254, 2012.

164. K. Roger, B. Cabane, and U. Olsson, “Emulsification through surfactant hydration: the PIC process revisited," Langmuir, vol. 27, no. 2, pp. 604-611, 2011.

165. K. Shinoda and H. Saito, "The effect of temperature on the phase equilibria and the types of dispersions of the ternary system composed of water, cyclohexane, and nonionic surfactant," J. Colloid Interface Sci., vol. 26, no. 1, pp. 70-74, 1968.

166. P. Walstra and P. E. A. Smulders, “Modern aspects of emulsion science,” by BP Binks, R. Soc. Chem. Inf. Serv. Cambridge, p. 56, 1998. 
167. G. W. J. Lee and T. F. Tadros, "Formation and stability of emulsions produced by dilution of emulsifiable concentrates. Part I. An investigation of the dispersion on dilution of emulsifiable concentrates containing cationic and non-ionic surfactants," Colloids and Surfaces, vol. 5, no. 2, pp. 105-115, 1982.

168. A. Beerbower and H. MW, “Application of the cohesive energy ratio (CER) concept to anionic emulsifiers," 1972.

169. C. Holtzscherer and F. Candau, "Application of the cohesive energy ratio concept (CER) to the formation of polymerizable microemulsions," Colloids and Surfaces, vol. 29, no. 4, pp. 411-423, 1988.

170. M. J. Rosen and J. T. Kunjappu, Surfactants and interfacial phenomena. John Wiley \& Sons, 2012.

171. F. Bouton, M. Durand, V. Nardello-Rataj, M. Serry, and J.-M. Aubry, "Classification of terpene oils using the fish diagrams and the Equivalent Alkane Carbon (EACN) scale," Colloids Surfaces A Physicochem. Eng. Asp., vol. 338, no. 1-3, pp. 142-147, 2009.

172. T. T. Nguyen, C. Morgan, L. Poindexter, and J. Fernandez, "Application of the hydrophilic-lipophilic deviation concept to surfactant characterization and surfactant selection for enhanced oil recovery," J. Surfactants Deterg., vol. 22, no. 5, pp. 983-999, 2019.

173. A. Witthayapanyanon, J. H. Harwell, and D. A. Sabatini, “Hydrophilic-lipophilic deviation (HLD) method for characterizing conventional and extended surfactants," J. Colloid Interface Sci., vol. 325, no. 1, pp. 259-266, 2008.

174. M. Budhathoki, T.-P. Hsu, P. Lohateeraparp, B. L. Roberts, B.-J. Shiau, and J. H. Harwell, “Design of an optimal middle phase microemulsion for ultra high saline brine using hydrophilic lipophilic deviation (HLD) method," Colloids Surfaces A Physicochem. Eng. Asp., vol. 488, pp. 36-45, 2016.

175. S. Wang et al., "Design of extended surfactant-only EOR formulations for an ultrahigh salinity oil field by using hydrophilic lipophilic deviation (HLD) approach: From laboratory screening to simulation," Fuel, vol. 254, p. 115698, 2019.

176. J. L. Salager, J. C. Morgan, R. S. Schechter, W. H. Wade, and E. Vasquez, “Optimum formulation of surfactant/water/oil systems for minimum interfacial tension or phase behavior," Soc. Pet. Eng. J., vol. 19, no. 02, pp. 107-115, 1979.

177. M. Bourrel, J. L. Salager, R. S. Schechter, and W. H. Wade, “A correlation for phase behavior of nonionic surfactants," J. Colloid Interface Sci., vol. 75, no. 2, pp. 451-461, 1980.

178. R. E. Antón, N. Garcés, and A. Yajure, “A correlation for three-phase behavior of cation1C surfactant-oil-water systems,” J. Dispers. Sci. Technol., vol. 18, no. 5, pp. 539-555, 1997.

179. J. L. Salager et al., "The emergence of formulation engineering in emulsion making - transferring know-how from research laboratory to plant," Polym. Int., vol. 52, no. 4, pp. 471-478, 2003.

180. J.-L. Salager, N. Marquez, A. Graciaa, and J. Lachaise, "Partitioning of ethoxylated octylphenol surfactants in microemulsionoil- water systems: Influence of temperature and relation between partitioning coefficient and physicochemical formulation," Langmuir, vol. 16, no. 13, pp. 5534-5539, 2000.

181. P. Nawavimarn, W. Rongsayamanont, T. Subsanguan, and E. Luepromchai, "Bio-based dispersants for fuel oil spill remediation based on the Hydrophilic-Lipophilic Deviation (HLD) concept and Box-Behnken design," Environ. Pollut., vol. 285, p. 117378, 2021.

182. S. Abbott, "Surfactant science: principles and practice," Update, vol. 1, pp. 2-26, 2016.

183. E. J. Acosta and A. S. Bhakta, “The HLD-NAC model for mixtures of ionic and nonionic surfactants," J. Surfactants Deterg., vol. 12, no. 1, pp. 7-19, 2009.

184. G. Panumonwatee, A. Charoensaeng, and N. Arpornpong, "Application of Hydrophilic-Lipophilic Deviation Equations to the Formulation of a Mixed-Surfactant Washing Agent for Crude Rice Bran Oil Removal from Spent Bleaching Earth," J. Surfactants Deterg., vol. 24, no. 6, pp. 949-962, 2021.

185. J.-L. Salager, R. E. Antón, J. M. Anderez, and J.-M. Aubry, “Formulation des micro-émulsions par la méthode HLD,” Tech. l'Ingénieur, vol. 157, p. 2001, 2001.

186. C. Chen, H. Shen, J. H. Harwell, and B.-J. Shiau, “Characterizing oil mixture and surfactant mixture via hydrophilic-lipophilic deviation (HLD) principle: an insight in consumer products development," Colloids Surfaces A Physicochem. Eng. Asp., p. 127599, 2021.

187. A. Skauge and P. Fotland, "Effect of pressure and temperature on the phase behavior of microemulsions," SPE Reserv. Eng., vol. 5, no. 04, pp. 601-608, 1990.

188. D. Schirone, G. Tartaro, L. Gentile, and G. Palazzo, “An HLD framework for cationic ammonium surfactants,” JCIS Open, p. 100033, 2021.

189. J.-L. Salager, R. Antón, J. Bullón, A. Forgiarini, and R. Marquez, “How to use the normalized hydrophilic-lipophilic deviation (HLDN) concept for the formulation of equilibrated and emulsified surfactant-oil-water systems for cosmetics and pharmaceutical products," Cosmetics, vol. 7, no. 3, p. 57, 2020.

190. E. J. Acosta, J. S. Yuan, and A. S. Bhakta, “The characteristic curvature of ionic surfactants," J. Surfactants Deterg., vol. 11, no. 2, pp. 145-158, 2008.

191. P. Kumar and K. L. Mittal, Handbook of microemulsion science and technology. CRC press, 1999.

192. R. Najjar, Microemulsions: an introduction to properties and applications. BoD-Books on Demand, 2012.

193. V. Kittithammavong, A. Charoensaeng, and S. Khaodhiar, “A Normalized HLD (HLDN) Tool for Optimal Salt-Concentration Prediction of Microemulsions," Appl. Sci., vol. 11, no. 19, p. 9151, 2021.

194. S. K. Kiran, E. J. Acosta, and K. Moran, “Evaluating the hydrophilic-lipophilic nature of asphaltenic oils and naphthenic amphiphiles using microemulsion models," J. Colloid Interface Sci., vol. 336, no. 1, pp. 304-313, 2009. 
195. J.-L. Salager et al., “Using emulsion inversion in industrial processes,” Adv. Colloid Interface Sci., vol. 108, pp. 259-272, 2004.

196. J.-L. Salager, “Emulsion phase inversion phenomena," in Emulsions and emulsion stability, CRC Press, 2005, pp. $205-246$. 